\title{
AN ANALYSIS OF THE IMPACT OF IMPLEMENTING A NEW INTERACTIVE VOICE RESPONSE SYSTEM (IVR) ON CLIENT EXPERIENCE IN THE CANADIAN BANKING INDUSTRY
}

\author{
by \\ Priscilla Manatsa \\ International Economics and Finance, Ryerson University, 2008
}

\begin{abstract}
A thesis presented to Ryerson University
in partial fulfilment of the requirements for the degree of Master of Science in Management in the program of Master of Science in Management
\end{abstract}

Toronto, Ontario, Canada, 2019

(C) Priscilla Manatsa, 2019 


\section{Author's Declaration}

I hereby declare that I am the sole author of this thesis. This is a true copy of the thesis, including any required final revisions, as accepted by the examiners.

I authorize Ryerson University to lend this thesis to other institutions or individuals for the purpose of the scholarly research.

I further authorize Ryerson University to reproduce this thesis by photocopying or by other means, in total or in part at the request of other institutions or individuals for the purpose of scholarly research.

I understand that my thesis may be made electronically available to the public. 


\title{
An analysis of the impact of implementing a new interactive voice response system (IVR) on client experience in the Canadian banking industry
}

Master of Science in Management, 2019

Priscilla Manatsa, Ryerson University

\begin{abstract}
Banks are constantly competing to find new ways to satisfy clients and meet their growing, heterogenous needs. Clients can access round the clock banking services worldwide. One way to access information is through Interactive Voice Response (IVR) systems. This research is an analysis of the process of implementing an IVR system and the impact on client experience using the case study of a Canadian bank. The research question is: "What is the impact of an IVR system upgrade on client experience in the Canadian banking industry?" The Productivity Paradox and the Unified Theory of Acceptance and Use of Technology model (UTAUT) are leveraged and a thematic analysis of the feedback provided from Net Promoter Score (NPS) surveys is done. The results show that although the IVR system can be an attractive automation interface for clients, there are many unanswered concerns about customer satisfaction as demonstrated by NPS feedback.
\end{abstract}




\section{Acknowledgements}

A special thanks to my supervisor Dr. Ron Babin, who provided invaluable guidance, insights and always challenged me, which made me truly experience every aspect of the research process. I would also like to thank my mom and dad for their undying support and for sparking my love of writing. 


\section{Table of Contents}

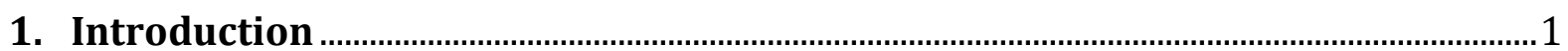

1.1 Channel and technology use in Canadian banking .........................................................1

1.2 What is an IVR system? .......................................................................................................

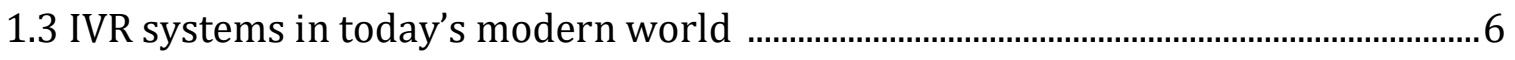

1.4 Motivation for doing research …………….............................................................................

2. Research Questions and Objectives ………………….................................................

3. Literature Review and Theoretical Framework ………...............................................12

3.1 a) Theoretical Framework - The Productivity Paradox.....................................................12

3.1b) Theoretical Framework - The Technology Adoption Model and extensions ....15

3.2 IVR system use in different sectors: banking and healthcare......................................19

3.3 Role of demographics..................................................................................................2

3.4 IVR systems upgrades and the Ontario wage increase ………………………….......23

3.5 Leveraging IVR systems to enhance client experience ................................................25

3.6a) Measuring client satisfaction with IVR systems: Containment and Task

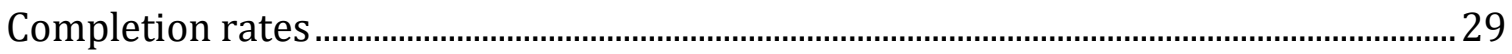

3.6b) Measuring client satisfaction with IVR systems: Net Promoter Score...................31

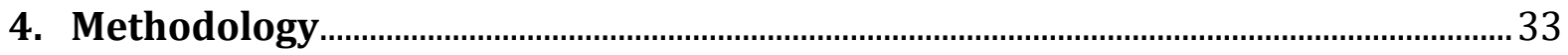

4.1 Surveys and Case Studies ......................................................................................................33

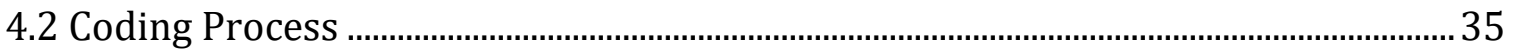

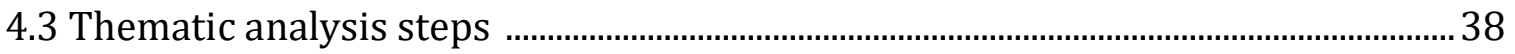

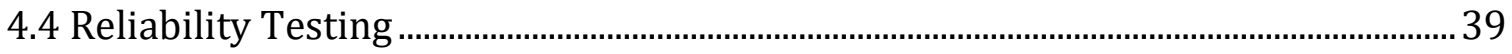




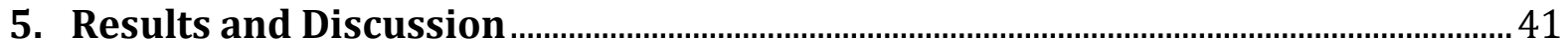

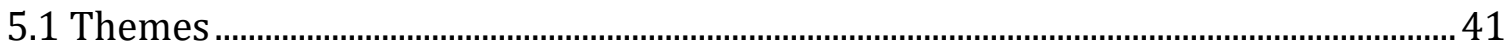

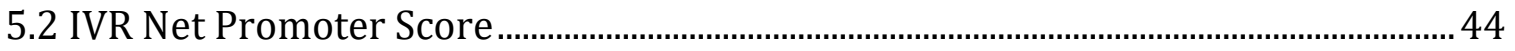

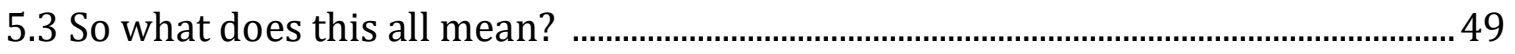

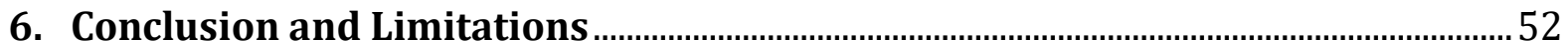

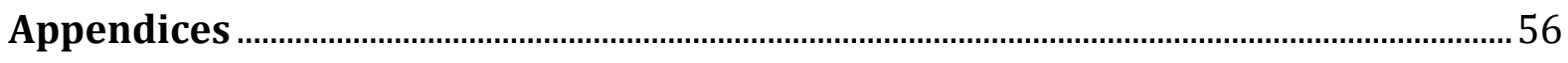

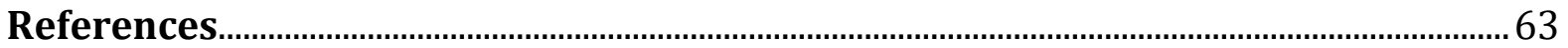

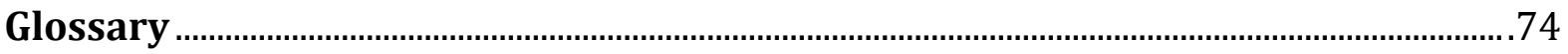




\section{List of Tables}

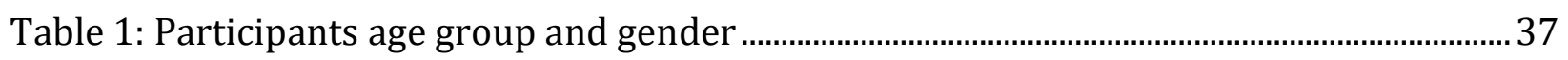

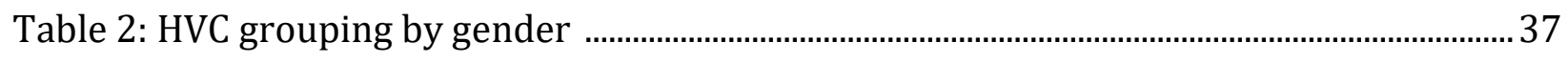

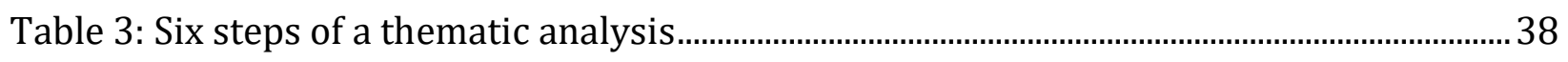

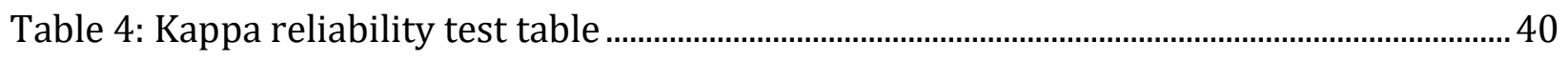

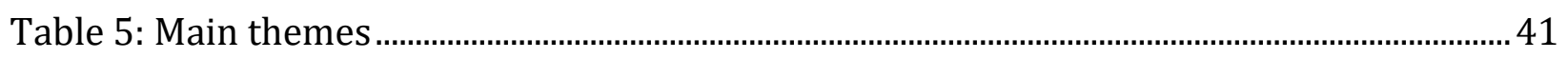

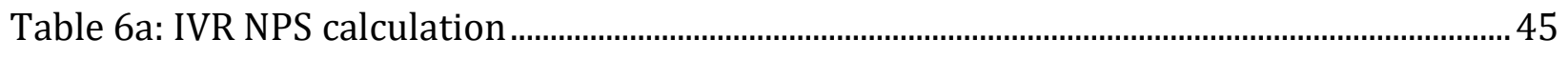

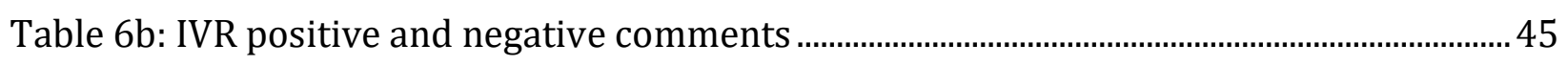

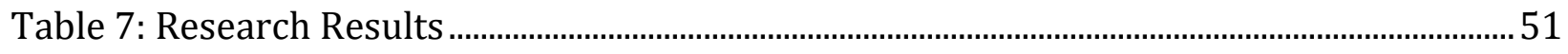




\section{List of Figures}

Figure 1: Channels most used by bank clients in Canada ..................................................................

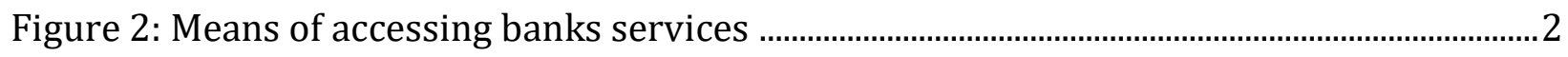

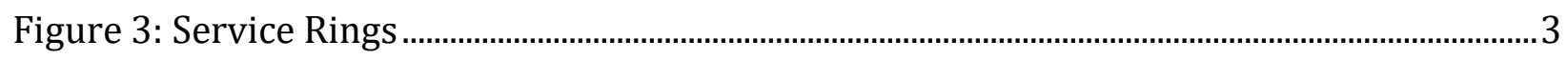

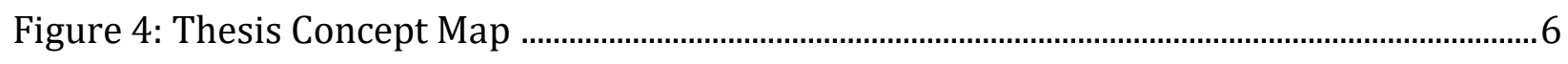

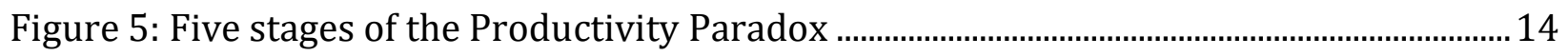

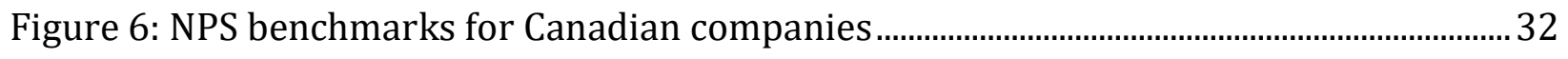

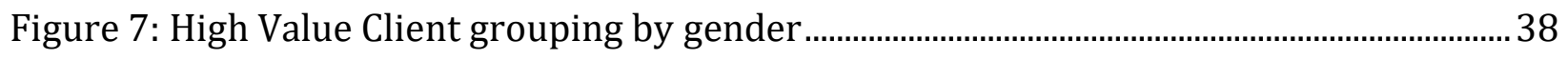

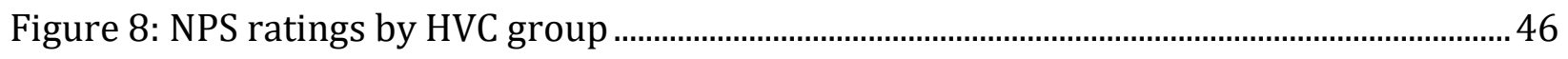

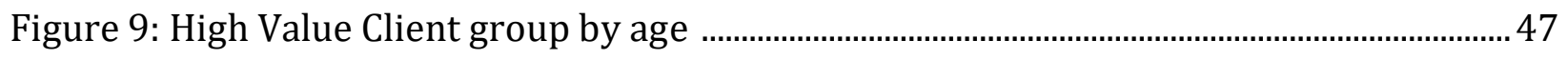

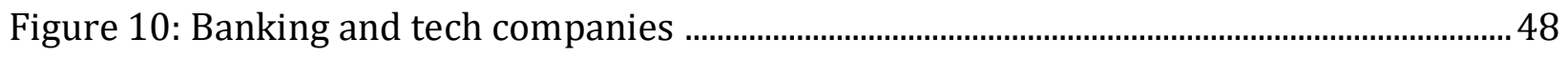




\section{List of Appendices}

Appendix A: Word Frequency chart ……………………..............................................................

Appendix B: Raw Data ........................................................................................................................5

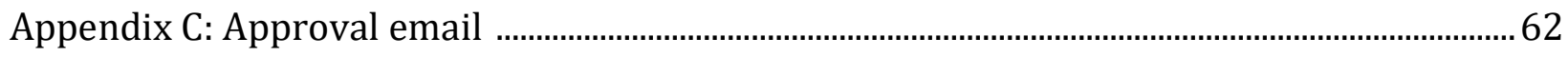

Appendix D: NPS survey questionnaire …………...........................................................................63 


\section{Introduction}

\subsection{Channel and technology use in Canadian banking}

Banks are institutions that provide difference products and services to clients to help them achieve their financial goals. Products and services offered in retail or consumer banking include investment services, mortgages, bank accounts, personal loans, debit and credit cards services. In the Canadian financial services industry, banks provide a number of channels for clients to access their products and services. Clients can visit a branch, use an Automated Teller Machine (ATM), make voice calls to call centre or use online and mobile banking. Call centres, which are also called contact centres, comprise of a set of resources including personnel, computers and telecommunication equipment used to deliver services via telephone lines (Gans, et al., 2003). Through online banking users can perform different financial transactions over the internet including deposits, bill payments and transfers (Frankenfield, 2019). Mobile banking is the use of cell phones and other types of handheld devices to access banking services via wireless networks (Zhou, et al., 2010).

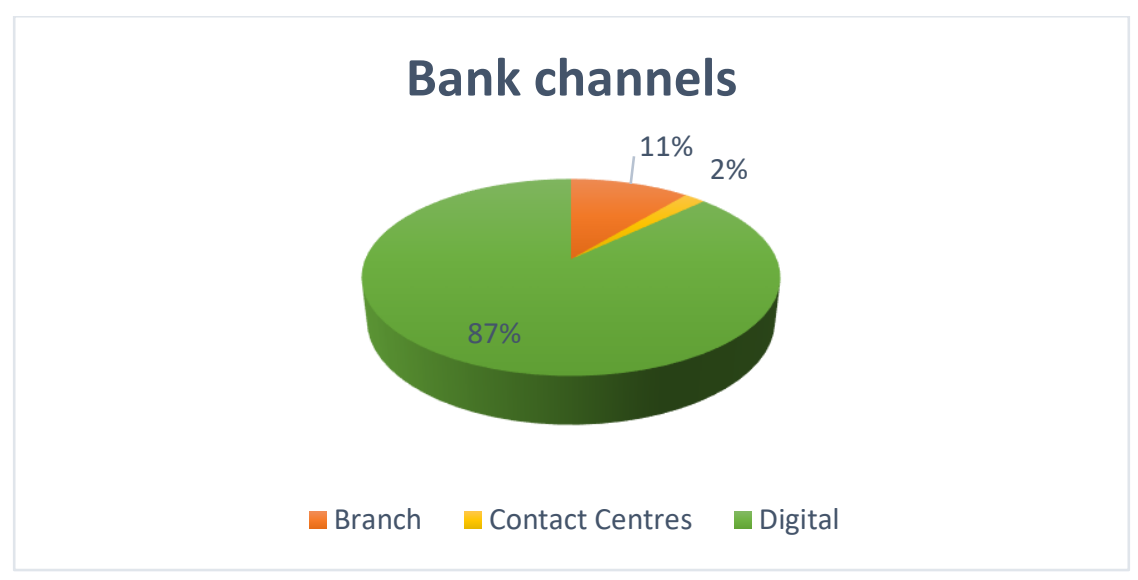

Figure 1: Channels most used by bank clients in Canada, IDC Financial Insights, Smythe \& Bremner, 2019 
Internet service is required to access mobile banking and nowadays, clients can also reach out to their bank through email, chat or social media. Banking services offered via the internet are collectively termed digital channels. Figure 1 above shows the distribution of the different channels used the most by Canadians when it comes to banking. $87 \%$ of clients use digital channels and the rest use the branch (in person or ATM) or contact centres. Figure 2 below highlights how frequently Canadian banking clients are accessing banking service through these different channels. 1002 Canadians, over 18 years were asked to rank how often they used five banking channels i.e. branch, ATM, call centre, online and mobile banking - either never, infrequently or frequently.

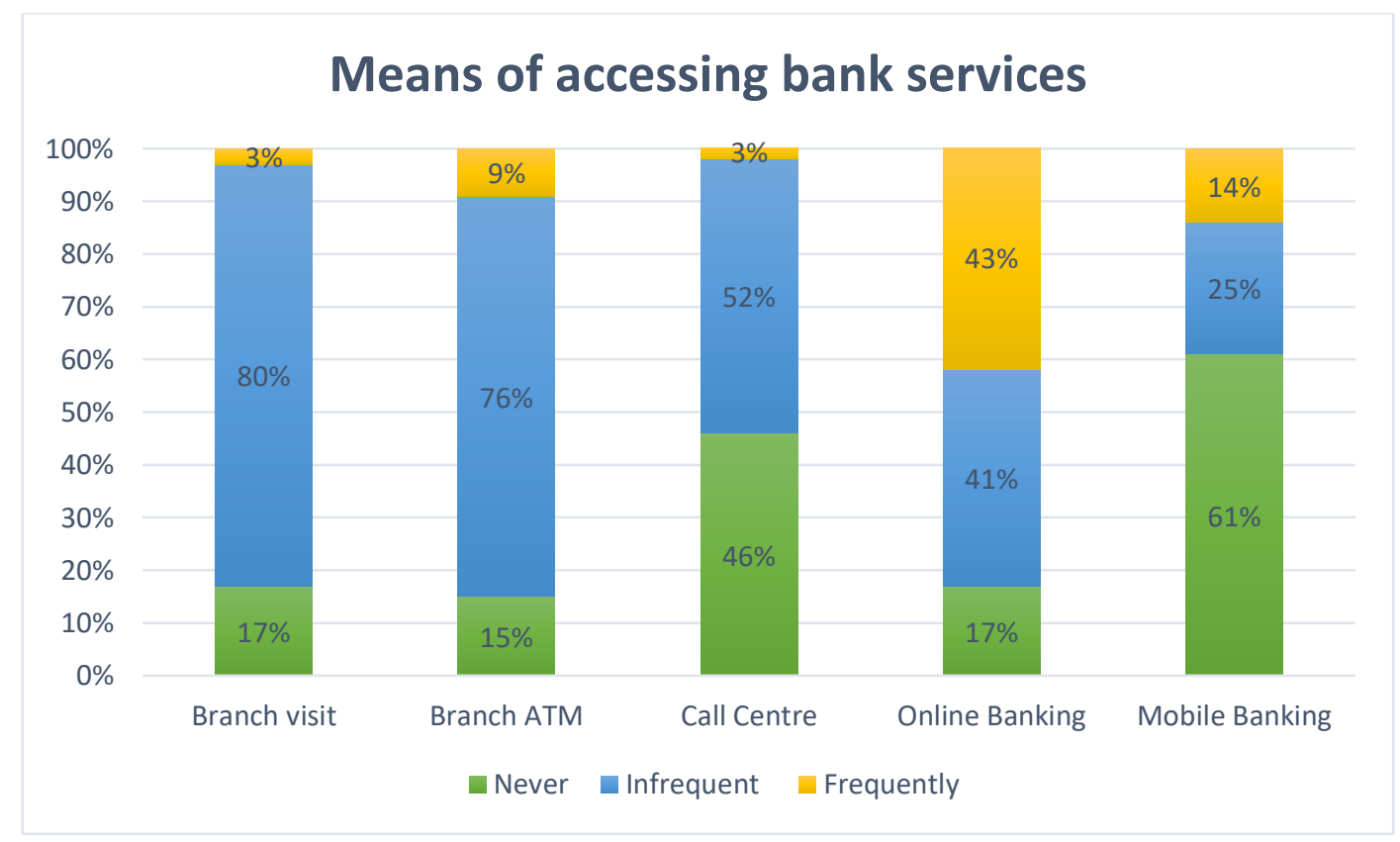

Figure 2: Means of accessing banks services, IDC Financial Insights, Smythe, et al., 2016b

Online banking was the most frequently used channel. With $43 \%$ of the respondents using it as the first choice to do banking, it is clear that there is shift from traditional brick 
and mortar branches to digital channels (Smythe, et al., 2016b). This was followed by mobile banking (14\%) and the branch ATM (9\%) as the second and third most frequently used channels respectively. Under call centres, $46 \%$ of respondents reported never calling in, 52\% called infrequently and 3\% called frequently (Smythe et al., 2016b). For the bank that will be used as a case study, the contact centre is still a major access point for clients. The corporate assumption is that clients will continue to use this channel and therefore investment in it will only grow. As more and more clients use online and mobile banking, the role of the contact centre is evolving to include assistance with troubleshooting issues clients are facing from other channels. One of the challenges banks will face as more clients migrate to online and mobile banking is to ensure that call centres stay aligned to continuously support this migration (Smythe et al., 2016b).

\section{Service Rings}

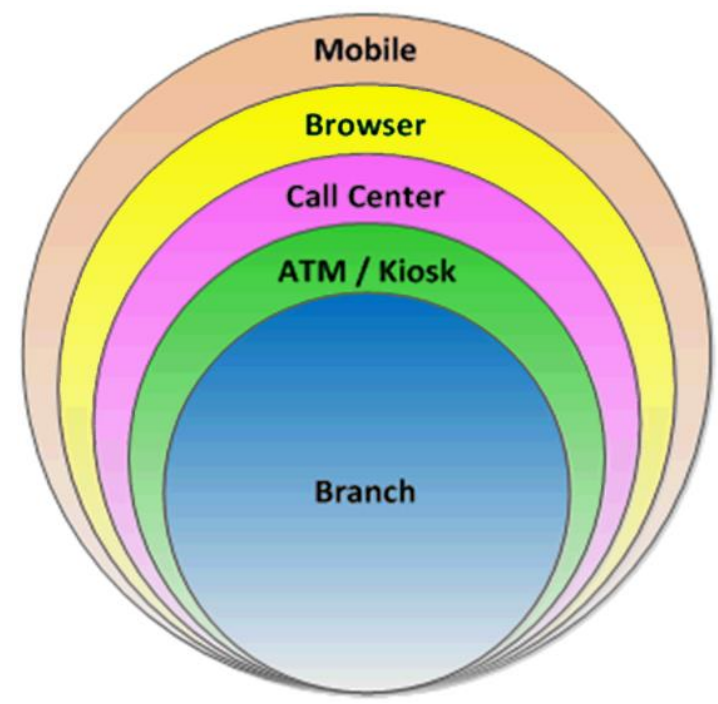

Figure 3: Service Rings, IDC Financial Insights, (Smythe, et al., 2016a) 
Banks, like many other organizations such as retail stores, will need to focus on creating an omnichannel customer experience. This is the ability for clients to be able to contact a company through an array of different channels and for the channels to be interconnected such that they are able to service the client seamlessly from start to end (Solomon, 2015). With the convergence of physical and digital channels, banks must continue to meet the needs of each client across all delivery channels - see Figure 3 (Smythe et al., 2016b).

\subsection{What is an IVR system?}

This paper will focus on the impact company telephony system upgrades have on clients, specifically changes to the Interactive Voice Response (IVR) system. IVR systems are the industrial version of an answering machine (Soujanya \& Kumar, 2010). They use voice prompts and menus to present information and options to callers who in turn use the touch tone keypad on their phone or spoken words (voice recognition) to input responses (Turner, 2018). From the options presented, callers elect from a voice menu that has prerecorded messages based on their needs (Vaishnavi \& Ganesh, 2014). This interaction typically takes place through a call centre. Call centres can handle an estimated $70 \%$ of all business interactions, assisting clients through humans or Self-Serve Technologies (SSTs) (Soujanya \& Kumar, 2010). SSTs allow customers to obtain information or service without the assistance of a live agent (customer service representative) and IVRs are a sub-system of SSTs (Vaishnavi \& Ganesh, 2014). Therefore, IVR systems are designed to help alleviate call volume and improve service levels in call centres (Miller, et al., 2011). They can route 
calls appropriately to live agents based on the client requests, provide information such as account balance or recent transactions or even allow clients to perform transactions such as bill payments.

Karademir \& Heves (2013) estimates the call volume IVR systems can handle being anywhere between $20-60 \%$, reducing the number of live agents required to answer calls at any particular time and improving service levels. Even though call centres enjoy the wage cost savings brought about by upgrades in phone technologies, the savings are not always easy to assess or measure (Karademir \& Heves, 2013). When organizations make changes to their IVR systems, the changes can be received with mixed reviews from both clients and call centre employees. IVR SST may miss the mark if clients are unable to get the information they need, become frustrated and have negative feelings towards the experience (Vaishnavi \& Ganesh, 2014).

Figure 4 below summarizes the thesis through a concept map, with each circle representing the different topics covered. From the literature, a theoretical framework as it relates to IVR system implementation will be discussed. This will be done from a client satisfaction standpoint. It will delve into factors that lead to frustration with IVR system upgrades using a case study of a company in the Canadian financial services industry. 


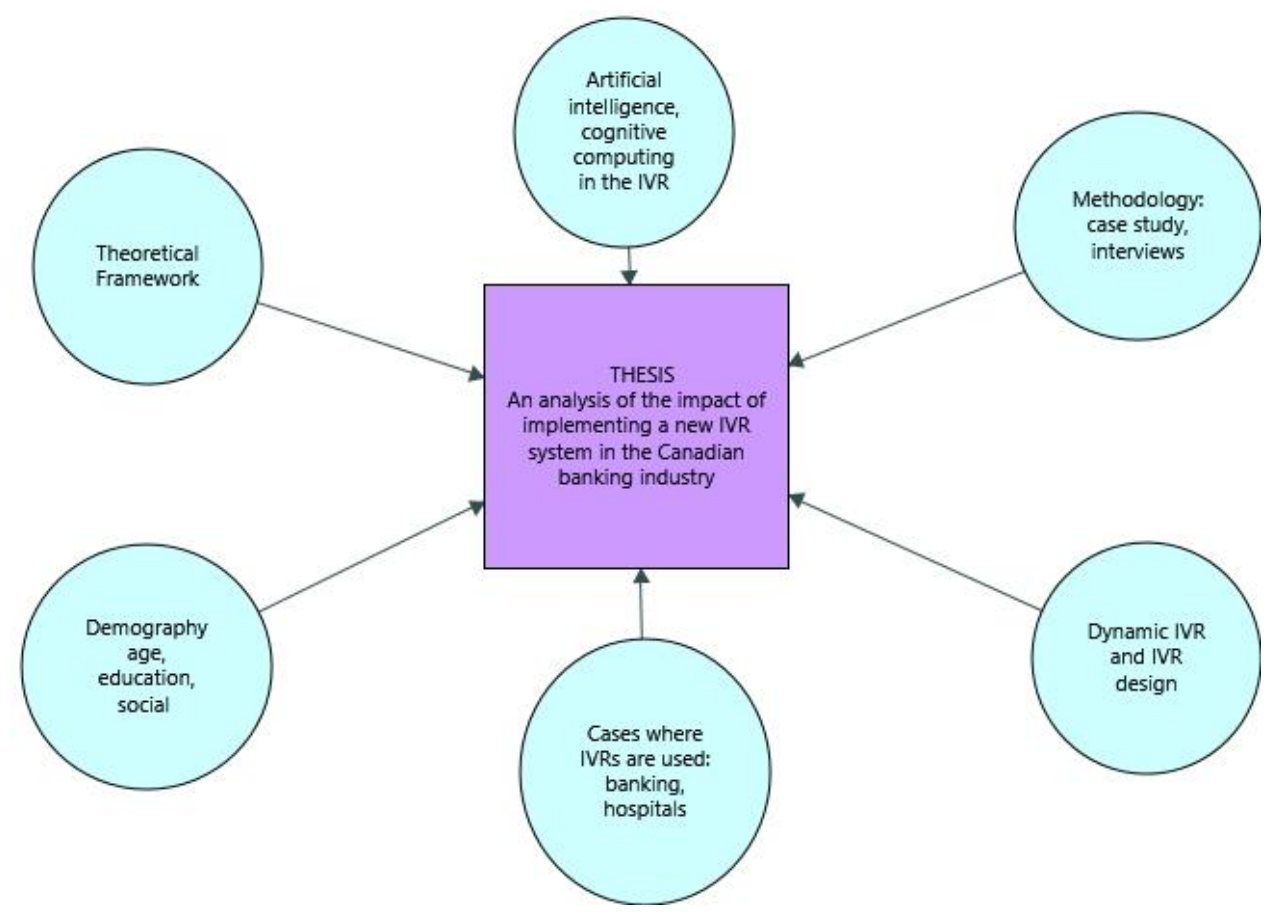

Figure 4: Thesis Concept Map

The role of demographics such as age, income and gender will be analyzed and tested to see how they affect the way new IVR SSTs are received. It will begin with a discussion on the theoretical framework shaping IVR transformation. This is followed by a discussion of different applications of IVR SSTs such as banking and healthcare, how demographics affect IVR system development and client satisfaction. Bank data collected from client Net Promoter Score (NPS) feedback will be analyzed to draw conclusions on how a new IVR system will be received.

\subsection{IVR systems in today's modern world}

Research begins with a challenge that management is facing and it must first be translated into a research problem (Smith, 2012). The research problem to be investigated 
in this paper emanated from undergoing an information technology (IT) system upgrade at a Canadian bank. One of the major reasons for implementing the IT system was to improve client experience across all call centres. A new Interactive Voice Response (IVR) system would reduce wait times, provide clients with timely information and allow them to complete financial transactions over the phone or through online and mobile banking. Employees and clients have experienced improvements, challenges and opportunities navigating the new IVR system through a learning curve.

With the growth of mobile phone use, call centres continue to see a transformation in the types of calls received. More than 5 billion people on earth have mobile phones and over half own smartphones (Taylor \& Silver, 2019). It is estimated that more people own mobile phones around the worldwide than toothbrushes (Kreyenhagen, 2018). Regardless of whether a country is an advanced or emerging economy, high income earners, younger people and the more educated are more likely to have smartphones (Taylor \& Silver, 2019).

In the banking world, mobile phones have increased online and mobile banking usage, in turn increasing the need for troubleshooting and technical support staff (Azeta et al., 2008). Technological advancement has invigorated discussions on how companies can adapt and use the momentum to survive and thrive in the $21^{\text {st }}$ century. A need exists based on providers in the market looking to help organizations leverage IVR systems in their day to day operations. Forbes.com emphasizes that companies must strike a balance between IVR systems, artificial intelligence (AI) and a well trained staff with excellent customer service skills (Chessman, 2017). The article goes on to caution against providing self-serve options only with no live agent support. The authors highlight that both IVR systems and 
call centre employees are necessary to achieve positive client experience and revenue growth.

Aspect, is a 45 year old telecommunications company that sells contact centre workforce and Self-Serve Technology (SST) solutions (Turner, 2018). The solutions include administering post inquiry surveys, automating the inbound customer interaction cycle, and building agent skill based routing (Turner, 2018). The IVR system provides SSTs, offering clients the opportunity to complete transactions without the need for assistance from a live agent. For Aspect, IVR SSTs are a tool to save time for both clients and employees and record invaluable information for creating predictive solutions and data driven strategies (Anderson, 2018). Research also shows that when it comes to the use of SSTs, $83 \%$ of clients will use self-serve options when available and $73 \%$ do want the ability to solve service or product issues on their own. And at the same time, client experience is paramount as $59 \%$ of these clients will not return after a bad experience (Campanella, 2018). $60-70 \%$ of calls do end up being connected to a live agent because clients are at times frustrated when asked to respond to IVR prompts and press numbers to get the information they need (Gomez, 2018).

\subsection{Motivation for doing research}

Motivation for doing social research can include personal, academic and social reasons (Blaikie, 2007). My motivation was a mixture of all three. Under personal reasons being part of an IT organizational change where a new IVR system was being implemented sparked my curiosity to find out what it took to execute such a monumental change. Could the learning curve be shortened and was there a theoretical framework to explain what 
was happening? As I was experiencing this organizational transformation, I wondered if there was a guide to follow rooted in research from the field. The challenge was to uncover if the research would apply to a company operating in the Canadian banking world. With these thoughts in mind, I embarked on a research journey to uncover the answer.

The study explored the impact of IVR SSTs on client satisfaction. It incorporated a case study of a major Canadian retail bank in the financial services industry which upgraded its contact centre IVR system in 2018. Consequently, the goal was to create a guide and starting point to help future companies that decide to overhaul their IVR systems, all the while maintaining client satisfaction. As well, the research provided insights to the bank on customer reaction to the new IVR. 


\section{Research Questions and Objectives}

The research question to be answered is: "What is the impact of an Interactive Voice Response (IVR) system upgrade on client satisfaction in the Canadian banking industry?" Another sub question from this over-arching question is "How is an industry-wide benchmark such as NPS affected by an IVR system upgrade?" The research questions will be answered from a client experience standpoint and the process will uncover elements that can lead to frustration with IVR system upgrades, using the case study of a Canadian retail bank. The role of demographics such as age, income and gender will be analyzed and tested to see how much they affect the reception of new IVR SSTs.

Research questions are answered using different research strategies and a deductive strategy is applied in this paper. Blaikie (2007) describes the deductive strategy as "testing theories by testing hypotheses derived from them" (pg. 10). Hypotheses created using deductive research strategies are commonly tested using quantitative methods; however qualitative methods can also be used (Blaikie, 2007). Qualitative data is in the form of words as opposed to numbers and is very common in the social sciences, with more and disciplines shifting to this paradigm (Miles \& Huberman, 1994).

An application to conduct this qualitative research endeavor was submitted to the Ryerson University Research Ethics Board (REB) and was advised via email on April 18, 2018 that "it does not seem like you will require REB approval as the main purposes of your research study is an evaluation of the customer service provided by a bank and usability testing of the voice-over option." A request was also submitted to the bank under review and prior written approval to proceed was obtained on August 2, 2018 (Appendix C). 
The next section contains a literature review on IVR systems, their implementation and application and the theoretical framework behind them. This is followed by a discussion of the research methodology and findings, concluding with recommendations and contributions the research will make. 


\section{Literature Review and Theoretical Framework}

The literature review will analyze the following topics as they relate to IVR systems: 1) Technology Adoption Models 2) IVR usage 3) Role of demographics 4) Ontario minimum wage increases 5) Enhancing client experience with IVR systems and finally 6) Measuring client IVR satisfaction. First, is a review of the theoretical models behind technology adoption followed by different industry applications of IVR systems. The role of demographics such as age and gender will be introduced and how such factors impact adoption of IVR technology. Next is a discussion on the impact of IVR SSTs on the workforce and wages with a focus on wage increases in the Canadian economy. The final part of the literature review will look at the impact of IVR systems on client experience and ways to measure overall satisfaction.

\section{1a) Theoretical Framework - The Productivity Paradox}

It is important to precede the next part with the definition of productivity.

Productivity is output per unit of input or the ratio of output per unit of work time (Roach, 2003). From a big picture perspective, productivity is important in determining the standard of living and wealth of a nation because what a nation consumes comes directly from what it produces (Brynjolfsson \& Hitt, 1998). The same logic applies to the individual company level. In the service sector, productivity can be very complicated to measure because the value added cannot always be easily captured (Roach, 2003). At the same time, a crucial connection exists between productivity and client experience because when 
properly measured, output should include the value created for consumers (Brynjolfsson \& Hitt, 1998).

The "Productivity Paradox," also called the "Solow computer paradox" is a business process phenomenon whereby the more technology a company adopts, the less productive the workers become (Dreyfuss et al., 2008). Steven Roach (2003), the chief economist for Morgan Stanley at the time, wrote several articles exploring why measured productivity growth rate slowed down substantially in the U.S. economy post 1970. After observing productivity in the service industry flatlining, he concluded that increases in computerization barely had an impact on the economic performance of information workers (Roach, 2003). Empirical evidence from 1970-1990 showed this peculiar discrepancy in business process analysis between IT (information technology) investment and IT performance, as productivity declined when new IT was introduced (MacDonald et al., 2000).

When automation was first launched in factories, pre1970, productivity was expected to increase by $3-4 \%$ after the upgrade was implemented. The reality was that return was minimal, around only $1 \%$ (Dreyfuss et al., 2008). This seemed counter intuitive. A number of theories were put forward including the lack of appropriate tools to measure productivity to a lag in the benefits of technology adaption being realized and MacDonald, et al., (2000) described five stages through which the paradox took course. 


\section{Five stages of the Productivity Paradox}

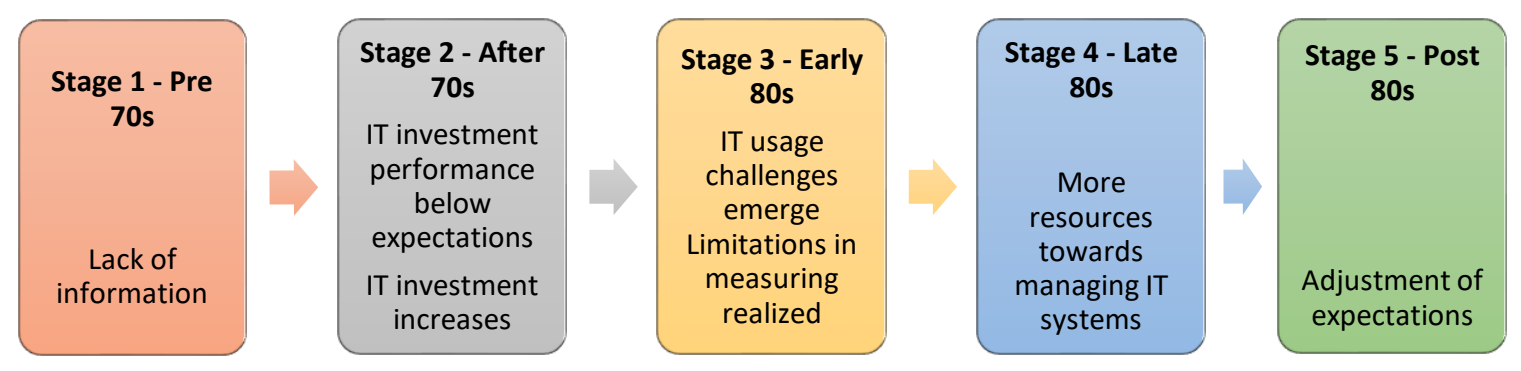

Figure 5 - As interpreted by author from Dreyfus et al., 2008

In the first stage, there was a lack of information available on the impact of IT investment but its introduction brought with it significant labour transformation expectations. Early adopters believed that IT would completely replace labour and labour productivity was used to measure IT impact. In the late 70 s, the second stage kicked in and it was becoming clear that the results of IT investment were less than expected. This did not stop companies from continuing to invest in IT development and only a few of them were measuring the impact of these investments (Dreyfuss et al., 2008). By the early 80s, most companies started to realize the limitations of using IT and the degree to which use brought about change. During the late 1980s, which was stage four, companies were putting their resources towards management of information systems instead and it was during this stage when the Productivity Paradox emerged. In the fifth and final stage, investments in IT shifted to telecommunications and there was an adjustment in expectations when it came to productivity (MacDonald et al., 2000).

The process of adopting new technology is complex - it does not occur in a vacuum and is by no means a single event (Straub, 2009). There are limitations to the Productivity 
Paradox and its application in today's information economy. The concern is how the Productivity Paradox was based on the experience of the 1980s, prior to the internet and consumer-based technologies such as mobile phone. Even as early as the 1990s, a shift was beginning to show in the results of IT investment. Brynjolfsson \& Hitt (1996) looked at survey data from over 367 firms during the period of 1987-1991. Each firm had at least one year of data consisting of the gross output produced, the value added and how the firms' results contributed to the GDP. The results were analyzed and the authors concluded that investment in information systems made a large contribution to the output of the participating firms, at times creating more value than spending from any other source (Brynjolfsson \& Hitt, 1996). In their analysis, the authors also reviewed other similar studies and found that at times the negative relationship observed between productivity growth and capital investment was possibly due to measurement problems. Others view that labour productivity, used to measure the impact of IT investment during the 70s and 80s, was already low and not a fair assessment tool (Triplett, 1999).

\section{1b) Theoretical Framework - The Technology Adoption Model and extensions}

One theoretical framework developed to explore this paradox is the Technology Acceptance Model (TAM) which can be used to help explain the way new technologies such as IVR SSTs are received by users (Davis, 1989). The model focuses on two aspects perceived usefulness and perceived ease of use, both of which are theorized to be important factors for system use (Venkatesh \& Davis, 2000). Perceived usefulness is the degree to which a person believes that using a particular system would enhance their job performance and perceived ease of use is the degree to which they believe they could use it 
effortlessly (Davis et al., 1989). After implementation of a new technology, the way users adopt it will depend on perceived usefulness and ease of use. As organizations perform IVR system upgrades, launch success is affected by how the technology is received by both clients and call centre employees. A series of questions were created and posed to the population to help determine perceived usefulness and ease of use. Based on his findings Davis (1989) concluded that if a system is easy to use, less effort will be required to operate it and the remaining effort can be allocated elsewhere.

TAM is an extension of Fishbein and Aizen's Theory of Reasoned Action (TRA) which looks at the relationship between a person's pre-existing attitude and their intentions and predicts that the individual's decision to behave in a particular way is based on their expectations of the outcome (Davis et al., 1989; Sheppard et al., 1988). Both the TRA and the TAM have behavioural elements and assume that individuals have no limitations when forming their intention to act. However, in real life business application some limitations do exist such as lack of freedom to act (Davis et al., 1989).

Over the years, TAM has been further studied and updated into the TAM2, TAM3 and the Unified Theory of Acceptance and Use of Technology (UTAUT) [Venkatesh \& Davis, 2000; Venkatesh et al., 2003; Venkatesh et al., 2016]. TAM2 was a theoretical extension of the TAM and tested perceived usefulness and usage intentions (Venkatesh \& Davis, 2000). The model collected longitudinal data from four different companies using four different systems $(n=156)$. In two of the companies, usage was mandatory and in the other two it was voluntary and system usage was measured at three points in time - preimplementation, one month post-implementation and three months post-implementation (Venkatesh \& Davis, 2000). In all four organizations tested results showed that the three 
measurement points (i.e. pre-implementation, one month post-implementation and three months post-implementation) were strongly supported, accounting for $40 \%-60 \%$ of the variance in usefulness perception and $34 \%-52 \%$ of the variance in usage intention (Venkatesh \& Davis, 2000).

The UTAUT, another extension of TAM, explains user intentions and usage behavior when new information systems are introduced (Venkatesh et al., 2003; Venkatesh et al., 2016). The theory has four key constructs 1) performance expectancy, 2) effort expectancy, 3) social influence and 4) facilitating conditions. Of these four constructs, the first three directly determine usage intention and behavior and the last one is a determinant of user behavior (Venkatesh et al., 2003). Demographics and other factors such as age, gender, experience and voluntariness of use are seen as moderators and impact the four key constructs on usage intention and behavior (Venkatesh et al., 2016). To test the model, the authors conducted a longitudinal study and the results showed it accounted for $70 \%$ of the variance in behavioural intention to use and 50\% in actual usage (Venkatesh et al., 2003). The UTAUT model and individual technology acceptance has been studied in a variety of settings including different users, different locations and at different times. Technology users can be categorized as employees, consumers and citizens and studies can be grouped based on the geographical locations of these users (Venkatesh et al., 2016). By the same token, technology adoption can be studied at different points in time i.e. pre-adoption, adoption and post adoption stages (Venkatesh et al., 2016). A study by Zhou, Lu, \& Wang (2010) analyzed user adoption for mobile banking to see the impact of factors such as the way the technology was perceived by the user or if it met their expectations. 250 participants who were clients of the two largest mobile telecommunications service 
providers in China were asked to complete a survey on their usage experience. The authors leverage the UTAUT model and found that technology perceptions such as perceived usefulness, perceived ease of use, interactivity, and relative advantage had significant effects on user adoption (Zhou, et al., 2010). Another study analyzed the perceptions of 243 people towards mobile services and technology in Finland, using the UTAUT model (Koivumäki, et al., 2008). They found that consumer perception to mobile services is not affected by how much time is spent on the device but how familiar they were with it and the skills they already had (Koivumäki, et al., 2008). Previous research has confirmed the robustness of UTAUT model and its main effects many times over but there is still minimal work examining the effects of age, gender, experience and voluntariness. These factors will be explored in the case study of the Canadian retail bank described in this paper and make a contribution to the existing body of knowledge on IVR SSTs.

The TAM and its successor the UTAUT are at times criticized for over simplifying user behavior and saying that it is based only on perceived ease of use and perceived usefulness (Straub, 2009). TAM fails to acknowledge the differences that exist at the individual level when it comes to technology adoption. It does not take into account many other factors that influence attitudes towards and the intention to use IT (Agarwal \& Prasad, 1999). As such, demographics such as age, gender, experience and voluntariness of use are added as moderators impacting the four key constructs on usage intention and behavior by Venkatesh et al., (2003) in the UTAUT to account for this. There are not many papers that adequately examine the link between technology use and individual performance. The paper by Sun et al., (2009) looked at the phenomenon and relied on usage frequency data measured by the users to determine technology use. Other papers used different measures 
to capture usage and further research is needed to measure the impact of technology use on individual outcomes (Venkatesh et al., 2016).

Even though companies upgrade information systems from time to time, they are continuously plagued by the issue of underutilized system usage (Venkatesh \& Davis, 2000). Further, this low usage of installed systems is one of the biggest factors underlying the "Productivity Paradox" and lowers the returns companies get from IT investment. Therefore, creating the necessary environment and conditions where IT systems can be embraced by users continues to be a main focus in research (Venkatesh \& Davis, 2000).

\subsection{IVR system use in different sectors - banking and healthcare}

IVR systems are mainly used to automate business processes for Customer Relationship Management (CRM) and typical applications include order taking, obtaining credit card or personal banking information, obtaining sensitive data in hospitals and clinics, televoting, etc., all of which can generate huge call volume (Thirumaran, Soni, \& Brendha, 2015). CRM is the process of acquiring, retaining, servicing and growing profitable customers (Farooqi \& Dhusia, 2011). As organizations work to achieve great results when it comes to CRM, investments in IVR technology are paramount. Regardless of the sector that the company is operating in, the IVR system should be optimally set up and operated in a way that delivers on the company's goals and allow seamless two-way communication with clients.

Banks are very focused on growth of distribution channels and extending selfservice options to clients so they can spend less time waiting at bank counters (Azeta, et al., 2008). Increasingly, Canadian banks are working to ensure that they are available to be 
reached by clients $24 / 7$ via as many different avenues as possible. The growth of online and mobile banking has simultaneously created the need for clients to call in for assistance completing transactions on their devices or help navigating the different services offered.

Sharit, et al., (2001) reported on IVR use in two different entities - a bank and a utility company. This case study focused on the usability of IVR systems while adjusting for speech compression levels to see if they were any age group differences in the results. The researchers found that more support for older adults is only required when they are somewhat unfamiliar with the IVR recording (Sharit et al., 2001). IVR systems give bank customers their transaction information in real time and provide the infrastructure that allows them to readily access authorized banking information systems (Azeta et al., 2008). This helps reduce the number of clients that would otherwise have had to line up at a brick and mortar branch and help banks manage queues especially during peak periods. IVR systems provide feasible alternatives for groups of banking clients that would otherwise not have had the access or options. These include individuals who are visually impaired, disabled or seniors (Azeta et al., 2008). Thirumaran et al. (2015) looked at how banks use IVR SSTs and concluded that they need them to be functional as they are an important component of CRM and assist contact centres to meet call volume demands. Further, old IVR systems more often than not lack the features necessary to keep up with call demand.

In the healthcare sector, IVR systems are a vehicle to collect information from patients in a discrete and confidential manner. This makes them ideal for collecting data in socially sensitive research for example reporting HIV high risk behaviour from participants. Using IVR technology means that participants from anywhere, even remote areas can take part in research. In this case, the IVR is used as a tool to collect data by 
fusing computer based self-interviewing with touch tone telephone technology. The participants enter their answers to prerecorded questions via the touch tone keypad and all the data, call timing and duration information is recorded in a server, eliminating the need for a live interviewer (Schroder \& Johnson, 2009). IVR technology has the capability to either receive and answer inbound calls or place outbound calls, depending on the needs of the user. Schroder \& Johnson (2009) go on to say that IVR systems can be programmed to provide automatic reminders and used to track participants of a study with ease.

\subsection{Role of demographics in IVR usage}

Attitudes towards IVR technology can differ depending on the age of the client. It means that a client's perception of IVR system upgrades may not be the same as what the company intends to achieve. This proved true in a survey of 912 participants that ranged in age, gender, income and educational background (Katz et al., 1997). The survey not only showed an inverse relationship between age and the ability to navigate computer data structures but that also younger respondents had less trouble navigating IVR systems than their older counterparts. Further, the random sample showed that age, gender, income and education were significant predictors of attitudes towards IVR systems with age being the most significant predictor.

Another survey by Dulude (2002) of 44 females - 22 seniors (65-86 years) and 22 university students (18-27 years) tasked with completing six IVR system exercises revealed that older people were less likely to find IVR systems convenient or likeable. The study looked at differences between old and young users of IVR technology to uncover how age plays a factor in adoption and use. In line with the researcher's expectations, a negative 
relationship emerged between overall satisfaction and age. The study also uncovered that senior participants were either proficient or not proficient when it came to task completion. Even though both groups pointed out design flaws such as unclear menu options and fast volume speed, the university students were able to easily overcome those challenges (Dulude, 2002).

Vaishnavi \& Ganesh (2014) conducted a research study and collected 627 surveys of mobile telecom customers in Chennai, India. $71.5 \%$ of the respondents were males and $28.5 \%$ were females. Their study looked at how demographic factors such as gender, age and education impacted IVR system perceived frustration for the customers of mobile telecommunications service providers in Chennai, using structured questionnaires. To explore patterns between different age groups, the participants were divided into the following cohorts: 16-25 (22\%), 26-35 (24\%), 36-45 (25\%), 46-55 (23\%) and >56 years (5\%). The findings revealed that the results of the 26-35-year olds were significantly different from all the other four cohorts, which the authors attributed to them using their mobile devises more frequently than the other participants (Vaishnavi and Ganesh, 2014). They also concluded that there was a positive relationship between age and perceived frustration i.e. the older the client, the more frustrated they were with using the telecommunications company IVR system. However, gender and education did not significantly impact client perceived frustration with IVR SSTs (Vaishnavi \& Ganesh, 2014). This presents an opportunity for companies to gain a better understanding of their client base and CRM. If they can successfully identify and segment the different groups they are catering to and the challenges they face, they can propose solutions to overcome the challenges and improve IVR system experience for all clients. 


\subsection{IVR systems upgrades and the Ontario minimum wage increase}

The Ontario Liberal government of Canada had planned to make changes to the province's labour laws with a gradual wage hike that would see the minimum wage increase over time from $\$ 11.60$ to $\$ 15$ by January 1st, 2019 ('ontario.ca', 2018). The new Conservative government voted in power in June 2018, went ahead with the planned increase but with a smaller hike to $\$ 14$ per hour (Loriggio, 2018). There are scheduled minimum wage increases in other Canadian provinces as well, slated over the two year period (Brouillette et al., 2017). Labour costs are a significant business expense and some companies spend upward of one third of their budget on wages (Adams et al., 2018). Bradshaw and Kingma (2019) peg employee wages as the biggest call centre expense and stress that effectively managing it is a crucial and strategic part of the business. This means companies need to become more efficient and explore alternative cost cutting options while still providing their market base with great client experience. In particular, as demonstrated within the bank, call centres employ a significant portion of entry level, minimum wage workers such as students and part time employees. A $\$ 1$ increase in wages has a big impact on call centre costs, encouraging many operations to seek efficiencies through improved technologies. Despite the $7 \%$ wage increase mandated by the government, the Canadian bank under review has opted to retain its call centre operations within Canada. The IVR system helps to provide cost savings that allow this to occur. Further, as call centre employees grow in their careers and move to other parts of the bank, the IVR system can help to manage turnover and maintain service level consistency for call volume.

There are a number of channels through which the provincial minimum wage hike can affect Canadian economic activity. Eight percent of Canadian workers receive the 
minimum wage and the literature shows that historically wage rate changes affect upwards of $15 \%$ of minimum wage workers (Brouillette et al., 2017). The minimum wage hike could increase the consumer price index (CPI) inflation by approximately 0.1 percentage points in 2017 and 2018 and reduce gross domestic product (GDP) by $0.1 \%$ by 2019 (Brouillette et al., 2017). Simulations have been done using the general equilibrium economic model.

Results suggest a minimum wage hike will cause real wages to go up, which in turn increases the marginal costs of firms and raise inflation as firms adjust prices in the short term. Labour demand will drop and reduce employment rates and labour hours worked, eventually weakening consumption. The higher inflation will cause interest rates to rise, offsetting the higher cost of labour (Brouillette et al., 2017). Preliminary results show that businesses have experienced layoffs, hiring freezes and increased automation as they adapt to increased wages (Tencer, 2019).

To reduce expenses brought about by the minimum wage hike, some companies will substitute minimum wage workers for higher paid, more productive ones and increase automation (Ngo et al., 2017). Businesses may respond to increased payroll costs by increasing prices, which may see sales falling and force them to reduce production and lay off workers (Ngo et al., 2017). However, a higher minimum wage means higher consumer spending as income for workers increase, stimulating the economy and creating more jobs. Consequently, increased household spending would offset job losses caused by the minimum wage hike (Ngo et al., 2017). In the short run output will remain unchanged but long run effects are quite ambiguous (Brouillette et al., 2017).

IVR SSTs can be leveraged to maximize the use of limited resources by automating as many call centre processes as possible. Savings from automation beyond reduced labour 
and marketing costs are lower training or recruitment costs, lower payroll taxes and health insurance premiums as well as reduced wait times (Adams et al., 2018). It is all about achieving more with less and an opportunity to put a lens on current business practices and how things are done and make the necessary changes to remain competitive. To ensure the right type of changes are implemented, call centres can reach out to clients or review existing client feedback from recorded calls or NPS surveys. They can find out what clients are saying about IVR SSTs and get insight into what services customers want automated (Adams et al., 2018). This also provides a great opportunity to implement changes and improve service. Minimum wage increases, mandated by government, focus company efforts on application of IVR technologies that can improve external customer service and reduce internal operating costs.

\subsection{Leveraging IVR systems to enhance client experience}

The popularity of IVR systems can be attributed to their versatility, increasing capabilities and declining operating costs (Perry \& Wingfield, 1994). With more people having access to mobile phones and enjoying the convenience of using them, the need for IVR SSTs is more important than ever. Clients do enjoy the convenience of being able to call companies at all hours of the day and night and perform different tasks like pay a telephone bill through their bank account or readily get general information such as hours of operation (Katz et al., 1997). Functions that can be performed through IVR systems include fund transfers, bill payments, creating standing orders, account balance inquiry, etc. (Azeta et al., 2008) 
As discussed earlier, in a medical environment IVR systems can also be used to collect and record confidential data from patients by researchers or doctors or guide patients to their doctor's extension line or remind them of an upcoming appointment. This means that privacy can be maintained and provides callers with another option besides speaking to a live agent. In certain cases where call centre employees are at different levels of tenure or training, calls can be segmented and directed accordingly to reach the agent best equipped to handle the call and this is called "skill based routing" (Gans et al., 2003). This creates efficiency and delivery of excellent client service as clients get access to the best trained agent to assist them in a timely fashion. It is clear that an IVR system overhaul, regardless of the industry that an organization operates, can have complex moving parts. Careful analysis must be done to ensure that everything is taken into consideration and any revisions made as necessary.

Client irritants when calling in to call centres are long wait or hold times, not being able to connect to a live agent and the lack of shortcuts in IVR system menu design (Miller et al., 2011). This has created the need to improve voice application development and cater to clients from different environments and with ever changing needs (Azeta et al., 2009). Developing cost-effective solutions for increasing client satisfaction with IVR technology in call centres is an important goal for many businesses using IVR systems and a number of recommendations have been put forward.

One way to address some of issues is to add algorithms in IVR system that can easily detect and route calls of clients facing difficulties such as older clients, using skills-based routing (Miller et al., 2011). Another recommendation that Miller et al., (2011). makes is to allow clients to pick between a male and female voice for presenting menu options. 
Personalized IVR systems offer an efficient speech interface by using speech enabled software which has voice recognition capabilities (Soujanya \& Kumar, 2010). Soujanya \& Kumar (2010) propose that by creating a system that provides more information and is interactive will result in a more comfortable experience for the user. The more comfortable the user is, the more information they are able to obtain and the better the experience will be.

As the needs of users change, sometimes even within a single interaction, IVR systems must be flexible, adaptable and able to mimic human reasoning as closely as possible (Azeta et al., 2009). Human interaction is very complex with a single conversation having over 750 million factors that can impact it, from customer and CSR emotions to different personality and communication styles (Miller, 2017). One way to account for this is using IVR technology with speech signals that deduce human emotion. Emotion recognition solutions have long been adopted in other applications such as talking toys and video games and can be applied to IVR systems by extracting emotion features based on client feedback in the IVR system (Sherif et al., 2003).

One of the main goals of IVR system implementation is to help alleviate call volume and operational costs in call centres. However some issues may arise and consequently result in clients avoiding using the IVR system altogether. Soujanya \& Kumar (2010) identified complicated menu and design issues, homogeneous service and customers feeling neglected because they are left to navigate the system on their own. A study by Katz et al, (1997) found that respondents disagreed that IVR systems put the client in control and believed they are less personal and show companies value more the time of their employees not that of clients. In their study, Sharit et al., (2001) sampled 195 people aged 
18-82 years to test IVR system usability for basic tasks and transactions for a bank and utility company. Based on their results they found that perception differences varied with each age group and identified that organizations need to provide elderly clients with more technical support.

Visual IVR is a support platform used to guide contact centre callers through a menu driven interface which provides web based support (Gomez, 2018). The company Radial provides customer care tools for companies using IVR systems and has been exploring visual IVR technology. Through a pilot with Michaels, the largest arts and crafts retail chain in America, Radial has had tremendous success when it comes to cost control and client satisfaction, measured through NPS. Initially, Michaels was using the traditional IVR system and had added self-serve options but achieved low adoption rates (Gomez, 2018). The goal was to improve containment rate which is normally pegged at 20-30\% for traditional IVRs. The pilot was done at Michaels' customer contact centre for order status and returns inquiries and the goal was to find cost effective, self-serve options clients could use after hours. Radial implemented a pilot using visual IVR to help the company achieve its goal. At the end of the pilot, Michaels saw a containment rate of $75 \%, 13 \mathrm{~K}$ calls that did not have to go to a live agent and a NPS score of $84 \%$ (Gomez, 2018). 85\% of clients would use mobile based visual IVRs for service inquiries if available (Campanella, 2018). Changing authentication to a two-step process that links clients over multiple channels and incorporate visual IVR systems. For example, if a client is having an online banking issue and they are calling into the contact centre for assistance, the IVR can send them a link to enter their online banking password and it can only be valid for the duration of the call. 
Artificial intelligence (AI) can help improve IVR system functionality in a number of ways. By predicting clients' intent, unnecessary interactions will be avoided and first contact resolution achieved. Through analyzing, capturing and organizing data and predicting outcomes, AI can also help detect fraud (Campanella, 2018). By proposing agent responses, AI can assist in the creation of a more personalized interaction which will positively impact client experience (Campanella, 2018).

\section{6a) Measuring client satisfaction with IVR systems: Containment and Task}

\section{Completion Rates}

IVR systems tend not to be dynamic in nature and fail to change as the needs of the user change (Inam, et al., 2017). This can be rectified by developing an IVR system that is adaptive and "intelligent" to address usability complaints and reduce user frustration (Thirumaran et al., 2015). Dulude (2002) pointed out that companies can still mitigate IVR system flaws even if they create a one size fits all design by focusing on usability. This can be achieved by reviewing what portion of clients' requests can be completed in the IVR without assistance. Ongoing monitoring will ensure that an IVR platform continues to perform optimally and deliver a positive client experience. However, as discussed in the Theoretical Framework section, this is a challenging task due to lack of information.

Businesses rely on indirect metrics like containment rates when assessing Return on Investment (ROI). (Gomez, 2018). Containment rate is the percentage of calls that end up in the IVR system and do not go to a live agent and are hence 'contained' (Leppick, 2012). It is calculated by dividing the number of contained calls by the total number of calls. The containment rate however does not capture whether a client was properly 
serviced or if they had a positive or negative experience (Leppick, 2012). This could be misleading. Task Completion Rate (TCR) is a more holistic measure because it helps to highlight problem areas and opportunities for improvement, while also indicating alignment with business objectives. (Microsoft Corporation, 2010). To see why TCR is a better measure of client satisfaction it is important to first get a better understanding of what a task is. A task encompasses a customer interaction, from identification of the client's intent to a final outcome (Microsoft Corporation, 2010). A task will end one of two ways with the client hanging up after completing everything they needed to in the IVR system or being routed to a live agent for assistance.

Microsoft Corporation (2010) goes on to provide a step by step blue print of what IVR system developers will need to measure TCR successfully. The first step would be to establish and program task end points so it will be possible to determine when tasks fail using standard Voice eXtensible Markup Language (Voice XML). Voice XML is the open standard markup language for voice applications and is considered the HTML of the voice web (Dahl, 2018). It is used for developing audio and voice response applications, such as banking systems and automated customer service portals. Task definition will be as follows (Microsoft Corporation, 2010):

- Task attempt - when a task begins

- Task success - when a task is completed successfully

- Task opt out - when the caller abandons the task by choosing the option to speak to a live agent or hanging up

- Task failure - when the caller is unable to complete the task 
This exercise will create a benchmark that will be used to measure success and failure against and the overall task success rate can be calculated as:

[number of task successes / number of task attempts]

TCR measures the impact of an IVR system while incorporating client experience in the calculation. TCR looks beyond containment rates and allows businesses to see if their IVR system changes are aligned with what the client feels they are able to accomplish.

\section{6b) Measuring client satisfaction with IVR systems: Net Promoter Score}

J.D. Power is a global market research company that creates benchmarks for different industries by using customer opinions and surveys worldwide to help companies improve satisfaction, performance and brand loyalty (jdpower.com, 2018). J.D. Power has collaborated and used methodology certified by Bain and Company, the co-creators of NPS to form the Bain Certified Net Promoter(jdpower.com, 2018). NPS benchmarking allows companies to use a consistent, accurate and well recognized methodology, provided by an independent agent and done to scale to allow comparisons across the industry. It is a consistent approach to compare performance with competitors and use results for goal setting and providing insights on where to improve (jdpower.com, 2018).

To derive NPS, respondents are asked how likely they are to recommend the bank to family and friends, on a scale of zero to 10 . The next step is to subtract the percentage of Detractors (those who give ratings of zero to six) from the percentage of Promoters (those who give ratings of nine and ten) [Markey, 2018]. The last step is to ask respondents why they have scored as they did and their answers are captured as NPS verbatims reviewed in this paper. Using NPS, companies can compare apples to apples as they can see how they 
fare relative to others. NPS is considered a good indicator of a company's future growth and a measure of brand loyalty (Markey, 2018).

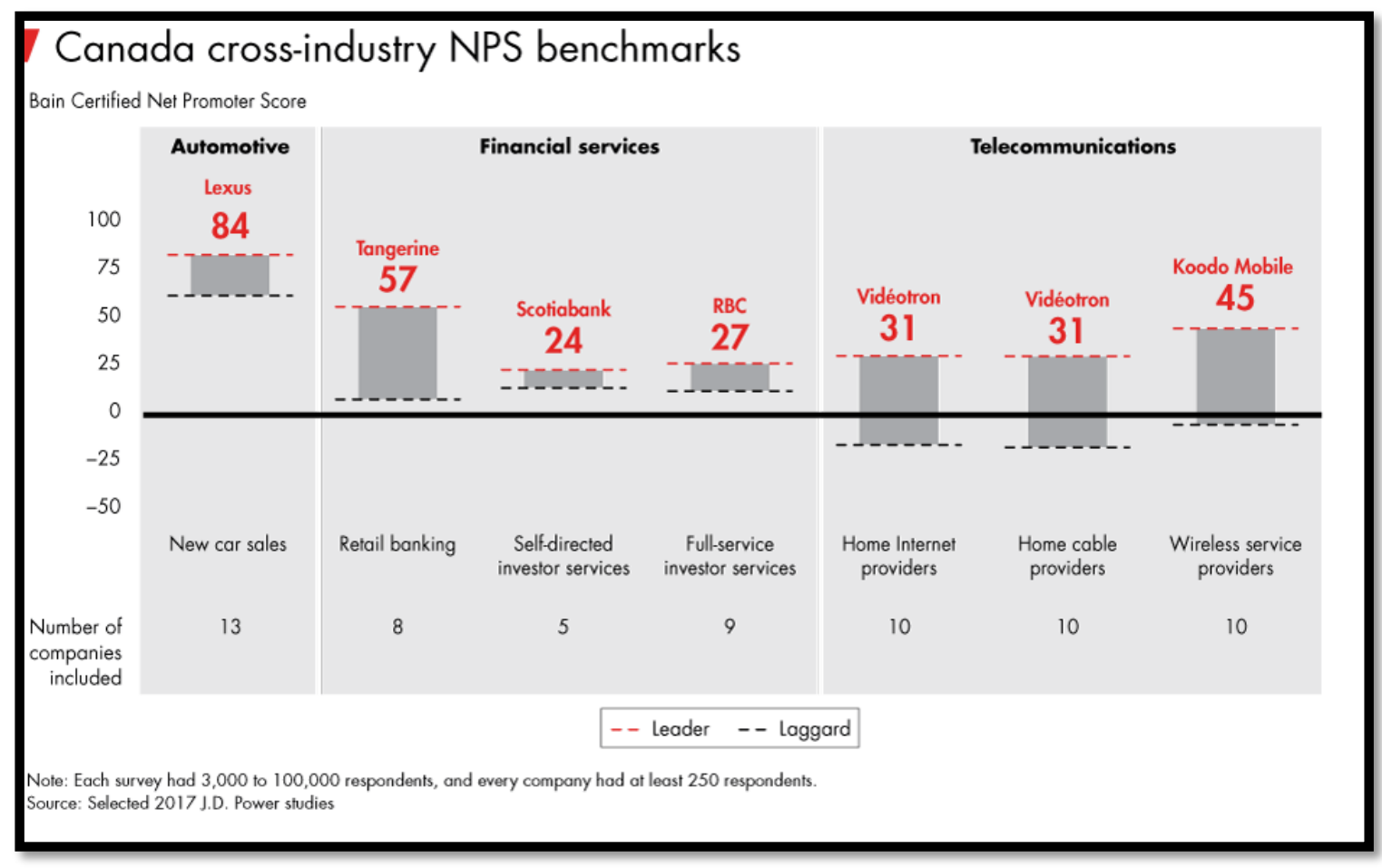

Figure 6: NPS benchmarks for Canadian companies, Bain and Company, 2018

Two industries that are regarded positively in Canada are retail banks and automakers with Lexus and Tangerine taking top scores (see Figure 6 above) [Markey, 2018]. 3,000 to 10,000 respondents were interviewed per sector and each company surveyed a minimum of 250 respondents to derive their NPS score. At least five companies were included in each sector to find the best performer per group. In the financial services sector, Tangerine, Scotiabank and Royal Bank Canada (RBC) were some of the Canadian banks participating and had NPS scores of 57, 24 and 27 respectively (Markey, 2018). 


\section{Methodology}

Investment in IT can be expensive and firms want to ensure that they get the best ROI. The primary reason companies invest in IT are to improve client experience and to reduce costs (Brynjolfsson \& Hitt, 1996). Below is an assessment of the steps taken to implement a new IVR system at a Canadian bank. The bank is used in this research as a case study. The case helps to understand the issues related to IVR adoption by customers. Surveys were conducted of bank customers who used the new IVR system and the results of the surveys are the basis for this research.

\subsection{Surveys and Case Studies}

One way to gather data when undertaking research is through surveys. Surveys consist of structured interviews done by an interviewer or written questionnaires completed by respondents (Bryman, et al., 2012). This allows for standardization in the questions asked and ease of categorization with the answers provided (Lewis-Beck, et al., 2004). They can be done face to face, over the phone or self-administered online or through traditional paper and pencil surveys (Smith, 2012). With the declining rate of face to face surveys, phone surveys are more commonly used and can gather information from a sample group of people with the purpose of using it to make generalizations to the larger population(Lewis-Beck, et al., 2004). There are many advantages for using phone interviews, which is how the NPS survey used for this research was done. Phone surveys are cost effective, easier to administer and reduce bias such as gender, class or ethnicity as the respondent is on the other side of the phone (Bryman et al., 2012). It takes considerably 
less time to complete than in person interviews and confidentiality can be easily maintained (Lewis-Beck, et al., 2004)

Yin (1984 p.23) describes a case study as 'an empirical inquiry that investigates a contemporary phenomenon within its real-life context especially when the boundaries between the phenomenon and context are not clearly evident.' Case studies have been seen as a type of research design, commonly used in qualitative research and as a method of selecting the source of data (Blaikie, 2007; Bryman \& Bell, 2007). Case studies allow a researcher to do a thorough analysis of a problem, within a specified time frame (Bryman \& Bell, 2007). Hence, a lone researcher, with limited resources can undertake the study of an in-depth issue (Blaikie, 2007). Often, it is seen as a unit of analysis, taking place within a bounded context (Miles \& Huberman, 1994). A case study can also be focused on an organization but analysis does extend to a single person, location or event (Bryman \& Bell, 2007). In many cases, case study research is longitudinal, meaning that it spans over time, to analyze how a particular situation evolves and the researcher is often a participant of the organization (Bryman \& Bell, 2007).

Case studies are done as a way to bring about change or to generate new theory (Blaikie, 2007) and can be exploratory, descriptive or explanatory in nature (Yin, 1989). The research questions being asked and the level of control the researcher has when it comes to the events being analyzed will determine the nature of the case study (Yin, 1989). The purpose of this thesis is to answer two research questions: "What is the impact of an IVR system upgrade on client satisfaction in the Canadian banking industry?" and "How an industry-wide benchmark such as NPS is affected by an IVR system upgrade?" Surveys answer 'who,' 'what,' 'where,' 'how many,' and 'how much,' questions and case studies 
answer 'how and why' questions (Yin, 1989). A combination of both a survey and case study where used in to answer the research questions in this paper. Client verbatim comments made about the new IVR system as part of NPS surveys administered from March-October 2018 for a Canadian bank were used.

\subsection{Coding process}

The main goal of doing surveys in qualitative research is to give all participants the same questions such that the responses can be aggregated and emerging themes can be analyzed (Bryman \& Bell, 2007; Tseng, 2008). The research involved analyzing transcribed IVR verbatim comments clients of a Canadian bank made in response to one of NPS survey questions (see Appendix D). Clients were asked a series of questions by an external organization, regarding their most recent call to the contact centre and verbatims were gathered from the answer provided to the last survey question "Are there any other opportunities that you would like to share with the bank?" The responses pertaining to the bank's new IVR system and the corresponding NPS ratings between March to October 2018 were aggregated. The IVR system was implemented at the start of 2018 and the period under review began three months post implementation. No pre-implementation NPS data regarding the IVR system was available for analysis as it was not captured at the time.

Familiarizing with the data was achieved through an iterative process of reading and re-reading the survey feedback. When a researcher invests time in the transcription process, it provides a first stage of analysis and sensitizes them to the more subtle features of the data (Braun \& Clarke, 2006; Tuckett, 2005). The transcripts were uploaded into a computer assisted qualitative data analysis software (CAQDAS) called NVivo 12 Plus, 
created by QSR International, to perform a thematic analysis. In their paper, Leech \& Onwuegbuzie (2011) discuss how CAQDAS such as NVivo can be used as a tool to assist in coding and analyzing huge amounts of qualitative data so that the underlying theories and relationships in the data can emerge. The authors do caution that the researcher should remain in control of the analysis and recognize that these programs are only meant to help the researcher analyze the data, not analyze the data for the researcher (Leech \& Onwuegbuzie, 2011; 'qsrinternational.com', 2018). Another important aspect of qualitative data analysis is data reduction. It is a process that involves "selecting, simplifying, abstracting and transforming the data that appear in written up field notes or transcriptions" (Miles \& Huberman, 1994).

At the beginning of the process there were 275 IVR system verbatim transcripts provided on a spreadsheet. Each observation contained information such as the participant's name, NPS category, interview date, and the comments made. Before anonymizing (deidentifying) the data, demographical attributes were added from the bank client's profile like gender, age, occupation, residence, years as a client and whether they were a high value client (HVC). HVCs are large net worth clients and have a strong relationship with the bank in terms of the value of their products and investments. The data reduction and clean-up process saw the elimination of client profiles that had missing information and reduced the number of observations in the spreadsheet to $\mathrm{n}=135$, ready to be imported into NVivo.

Below in Table 1 is a breakdown of the survey participants based on different attributes. The gender breakdown of the participants was $63 \%$ males and $37 \%$ females. 


\begin{tabular}{|c|c|c|c|c|c|c|c|}
\hline $\begin{array}{c}\text { Age } \\
\text { Range }\end{array}$ & $\begin{array}{c}\text { Gen Z } \\
(\mathbf{0 - 1 7 )}\end{array}$ & $\begin{array}{c}\text { Millenni } \\
\text { als (18- } \\
\mathbf{3 4 )}\end{array}$ & $\begin{array}{c}\text { Gen X } \\
\mathbf{( 3 5 - 5 0 )}\end{array}$ & $\begin{array}{c}\text { Baby } \\
\text { Boomers } \\
\mathbf{( 5 1 - 7 0 )}\end{array}$ & $\begin{array}{c}\text { Elderly } \\
\mathbf{( 7 1 - 1 0 0 )}\end{array}$ & Total & Percent \\
\hline Male & 0 & 30 & 30 & 24 & 1 & 85 & $63 \%$ \\
\hline Female & 0 & 16 & 12 & 21 & 1 & 50 & $37 \%$ \\
\hline Total & $\mathbf{0}$ & $\mathbf{4 6}$ & $\mathbf{4 2}$ & $\mathbf{4 5}$ & $\mathbf{2}$ & $\mathbf{1 3 5}$ & $\mathbf{1 0 0 \%}$ \\
\hline Percent & $\mathbf{0 \%}$ & $\mathbf{3 4 \%}$ & $\mathbf{3 1 \%}$ & $\mathbf{3 3 \%}$ & $\mathbf{1 \%}$ & $\mathbf{1 0 0 \%}$ & \\
\hline
\end{tabular}

Table 1: Participants age group and gender

The data was further grouped into different age cohorts to explore demographical patterns and trends. Generation Z consisted of 0-17-year-old participants and there were no people for this group. Millennials, also referred to as Generation Y, consisted of 18-34year-olds and this cohort had twice as many males as females. Generation X members were 35-50-year-old and had a male to female ratio of 2:1. There were 45 Baby Boomers (51-70 years) and they were almost evenly split between male and females. The last and smallest group were elderly clients aged 71 years with one male and one female. The next step was to import the spreadsheet into NVivo to begin a thematic analysis. Thematic analysis is a method of identifying, analyzing and reporting patterns (themes) within data" (Braun \& Clarke, 2006). It organizes data e.g. interviews and describes it in rich detail by searching across the data to find meaningful patterns (Braun \& Clarke, 2006). Figure 7 below shows the breakdown of HVCs and non-HVCs based on gender. Even though there were more men in the sample, the results show that there was a 2:1 ratio between HVCs and non-HVCs.

\begin{tabular}{cccc} 
& \multicolumn{3}{c}{ non- } \\
& HVC & HVC & Total \\
Male & 27 & 58 & $\mathbf{8 5}$ \\
Female & 18 & 32 & $\mathbf{5 0}$ \\
Total & $\mathbf{4 5}$ & $\mathbf{9 0}$ & $\mathbf{1 3 5}$
\end{tabular}

Table 2: HVC grouping by gender 


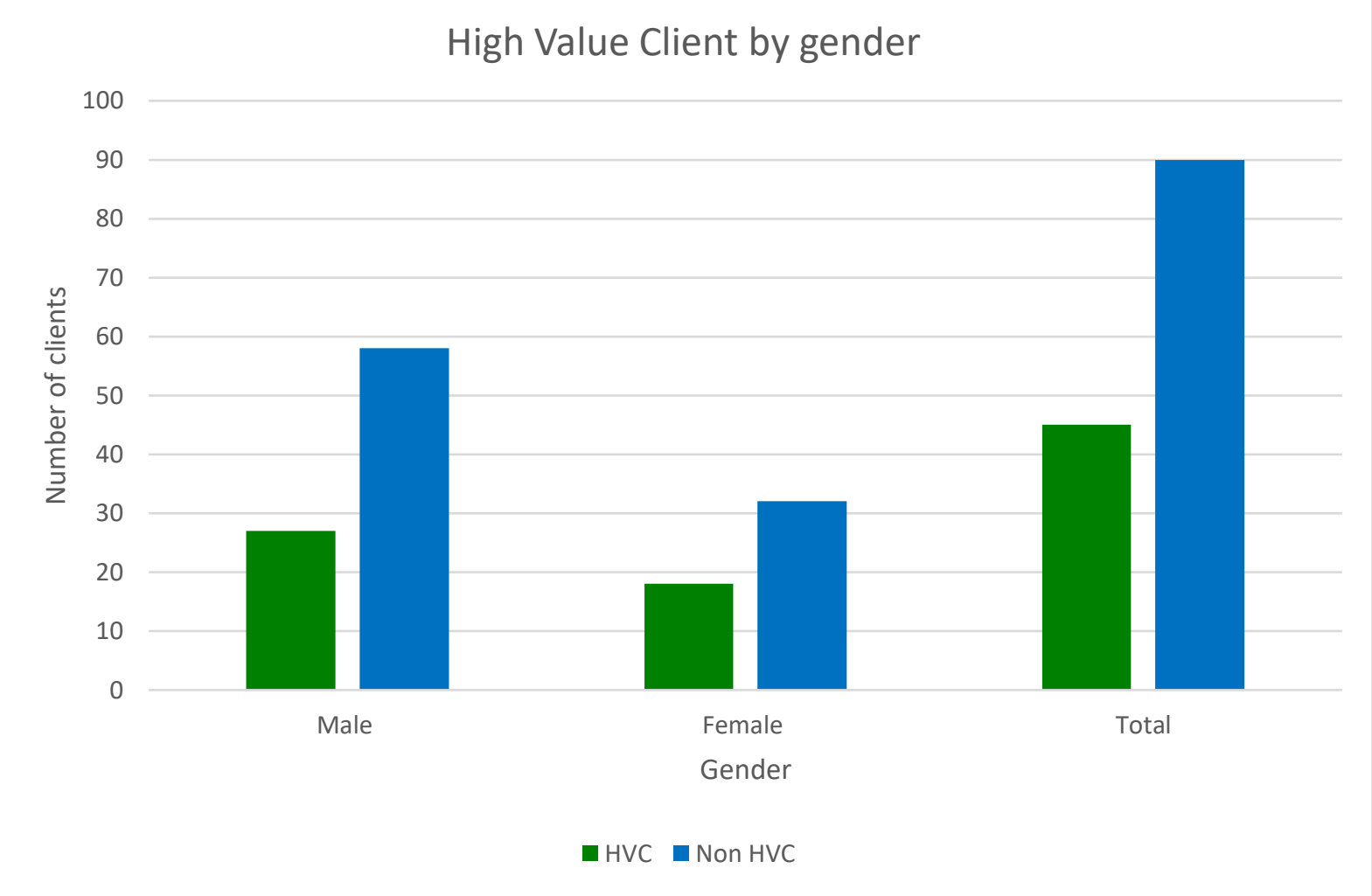

Figure 7: High Value Client grouping by gender

\subsection{Thematic analysis steps}

The table below summarizes how to do a thematic analysis in six simple steps.

\section{Phase}

1. Familiarizing yourself with your data

2. Generating initial codes

3. Searching for themes

4. Reviewing themes

5. Defining and naming themes

\section{Descriptions of the process}

Transcribing data (if necessary), reading and re-reading the data, noting down initial ideas.

Coding interesting features of the data in a systematic fashion across the entire data set, collating data relevant to each code.

Collating codes into potential themes, gathering all data relevant to each potential theme.

Checking if the themes work in relation to the coded extracts (Level 1) and the entire data set (Level 2), generating a thematic 'map' of the analysis.

Ongoing analysis to refine the specifics of each theme, and the overall story the analysis tells, generating clear definitions and names for each theme. 

6. Producing the report The final opportunity for analysis. Selection of vivid, compelling extract examples, final analysis of selected extracts, relating back of the analysis to the research question and literature, producing a scholarly report of the analysis.

Table 3: Adopted from Braun \& Clarke, 2006

After reading the data numerous times over, codes were created. Codes are "labels used to assign meaning to the inferential information compiled" (p56) (Miles \& Huberman, 1994). Main themes emerge by collating the codes and repeating this process to uncover clear definitions of the themes. The last step required going back to link themes to the research question and literature review before creating a final report of the analysis (Braun \& Clarke, 2006).

\subsection{Reliability testing}

Reliability "refers to the consistency of a measure of a concept" and validity "refers to the issue of whether or not an indicator that is devised to gauge a concept really measures it." (p164-5) (Bryman \& Bell, 2007). It measure the trustworthiness of the coding process (Bazeley \& Jackson, 2013). Reliability was carried out by conducting a reliability analysis where a second coder was provided with the theme definitions and asked them to code approximately $20 \%$ of the data independently $(n=29)$. This coding comparison query measured inter-rater reliability - the degree of agreement between the users ('qsrinternational.com', 2018). The next step was to run the Kappa statistic in NVivo 12 Plus, which is a statistical measure which takes into account the amount of agreement expected to occur through chance and got an average result of 0.8866 across different themes ('qsrinternational.com', 2018). Table 4 below shows the Nvivo reliability test. 


\begin{tabular}{|c|c|c|c|c|c|c|c|}
\hline Code & Kappa & $\begin{array}{r}\text { Agreement } \\
(\%)\end{array}$ & $\begin{array}{l}\mathrm{A} \text { and } \\
\mathrm{B}(\%)\end{array}$ & $\begin{array}{l}\text { Not A and } \\
\text { Not B (\%) }\end{array}$ & $\begin{array}{r}\text { Disagreement } \\
(\%)\end{array}$ & $\begin{array}{r}A \text { and } \\
\text { Not B } \\
(\%)\end{array}$ & $\begin{array}{r}B \text { and } \\
\text { Not A } \\
(\%)\end{array}$ \\
\hline Dropped calls & 1 & 100 & 1.03 & 98.97 & 0 & 0 & 0 \\
\hline Harder to pay bills & 1 & 100 & 0.94 & 99.06 & 0 & 0 & 0 \\
\hline Immediate access to agent & 0.7347 & 98.19 & 2.63 & 95.56 & 1.81 & 0.87 & 0.94 \\
\hline Key in issue & 1 & 100 & 0.33 & 99.67 & 0 & 0 & 0 \\
\hline Long or confusing prompts & 0.8089 & 97.76 & 5.13 & 92.62 & 2.24 & 1.96 & 0.28 \\
\hline Slower than previous IVR & 0.6625 & 99.69 & 0.31 & 99.37 & 0.31 & 0 & 0.31 \\
\hline Too many ads & 1 & 100 & 0.4 & 99.6 & 0 & 0 & 0 \\
\hline Average & 0.8866 & & & & & & \\
\hline
\end{tabular}

Table 4: Kappa reliability test table

A Kappa value below 0.40 shows poor agreement, $0.40-0.75$ is fair/good and anything above 0.75 is excellent. Other authors recommend a higher value of about 8090\% (Bryman \& Bell, 2007; Roberts et al., 2006). If the users are in complete agreement Kappa is 1 and if there is no agreement Kappa is 0 . The green columns show the percentage of agreement and the red column show the percentage of disagreement. With user A being the author and user B the second coder, "A and B" column shows the percentage of data coded to the selected nodes by bother user A and B (Bazeley \& Jackson, 2013). The "Not A and Not B" column is the percentage of data coded by neither user A nor B and the "Agreement" column is the sum of the two columns. The red columns represent the same information but for disagreement between the users (Bazeley \& Jackson, 2013; 'qsrinternational.com', 2018). According to Bryman \& Bell (2007), there are different types of validity including face validity, which can be established through asking others with experience and expertise in the field to judge your work. This means regular supervision and peer reviews will increase validity and avoid researcher bias (Roberts et al., 2006). Oversight from my supervisor and the second coder helped facilitate this condition. 


\section{Results and Discussion}

\subsection{Themes}

Numerous themes started to emerge during the coding process and are summarized below in Table 5. Appendix B provides a breakdown of each theme by participant ( $\mathrm{n}=135)$.

\begin{tabular}{|c|c|}
\hline Themes (Times coded) & Explanation \\
\hline $\begin{array}{l}\text { Long and confusing prompts } \\
\text { (79) }\end{array}$ & $\begin{array}{l}\text { Clients unable to navigate the menu to find the option } \\
\text { that best matches the reason for calling }\end{array}$ \\
\hline $\begin{array}{l}\text { Immediate access to an } \\
\text { agent (51) }\end{array}$ & $\begin{array}{l}\text { When clients want an option that connects directly to a } \\
\text { live person }\end{array}$ \\
\hline Great customer service (24) & $\begin{array}{l}\text { When clients have a great experience after speaking } \\
\text { directly to a live agent }\end{array}$ \\
\hline $\begin{array}{l}\text { Long wait times \& poor SVLs } \\
\text { (20) }\end{array}$ & Reduce wait times to connect to a live agent \\
\hline Key in issue (15) & $\begin{array}{l}\text { When the IVR is unable to recognize the information } \\
\text { entered by clients }\end{array}$ \\
\hline Call back feature issue (13) & $\begin{array}{l}\text { Problems with the IVR feature meant to put a client's call } \\
\text { in priority sequence \& call them back when the next CSR } \\
\text { becomes available }\end{array}$ \\
\hline $\begin{array}{l}\text { Worse than previous IVR } \\
\text { (12) }\end{array}$ & $\begin{array}{l}\text { Complaints about the old IVR being able to complete } \\
\text { tasks better than the new system }\end{array}$ \\
\hline Dropped calls (10) & When a call disconnects unexpectedly \\
\hline Harder to pay bills (8) & $\begin{array}{l}\text { Bill payment process is harder to complete on new IVR } \\
\text { system than it was on previous system }\end{array}$ \\
\hline $\begin{array}{l}\text { Better ads/relevant } \\
\text { information in IVR (6) }\end{array}$ & $\begin{array}{l}\text { A lot of information provided about products available } \\
\text { to clients as they navigate the IVR }\end{array}$ \\
\hline Better music (3) & Opportunity to provide different musical genres \\
\hline
\end{tabular}

Table 5: Main themes

The most recurring theme was the complexity of the menu prompts with comparisons being made to "going down too many roads" by Client 80 or "being dragged around like a monkey," by Client 114 . The menu did not always present options matching the reason clients were calling. Too many options left clients overwhelmed and meant they spent more time in the IVR than they intended to, creating a never-ending cycle. Therefore, 
striking a balance between clarity and a condensed menu will improve overall IVR experience. Frustration was voiced over the inability to immediately connect to a live agent especially after spending so much time stuck in the IVR. Those that talked about long and confusing prompts almost always mentioned how they had trouble reaching a live agent.

This resulted in 'immediate access to a live agent' being the second most coded theme. It aligned with what Vaishnavi \& Ganesh (2014) found in their study. They identified client irritants when calling call centres as long wait times, not being able to connect to a live agent and lack of shortcuts in the IVR menu design. The authors surveyed 627 telecom clients to understand perceived IVR frustration based on demographic variables of age, gender and education. (Vaishnavi \& Ganesh, 2014). Better clarity in the menu options will assist users in making the right choice. Using IVR call history information to anticipate why a client is calling can streamline menu options according to each caller. For example, if an elderly client always calls at the end of the month to check their bank balance in anticipation of a pension cheque, the IVR can leverage the data to customize their IVR menu picks. The client can then be asked for example to press 'option one' if they are calling about a recent direct deposit or 'option two' if they are calling about the same issue discussed during their last call.

For the third theme - 'great customer service' clients showed appreciation for the effort made to better the IVR system. One client shared that they loved how it was available $24 / 7$ and allowed them to always access their banking. Another client was eager to acknowledge that making improvements does take time and added "Nobody is perfect, your system has to improve and you are trying!" More often than not, clients only spoke of their satisfaction when the interaction involved speaking to a live agent during the call. 
The next two recurring themes after 'great customer service' were 'improving service levels' and 'using the call back feature.' The call back feature in the IVR system means clients can rest easy knowing that their place in line will be kept in priority sequence and they will receive a call back through the IVR system once their turn arrives. Participants identified a few issues including the feature not being triggered despite being on hold for a long time. Other times, it malfunctioned and would initiate a call back over and over again even though there was no available agent to take the call. In one instance, it called the participant over three times over a five-minute period. Feedback provided was that the call back feature should allow callers to go back into the queue if they decided not to proceed after initiating it.

The three themes - 'key in issue,' 'worse than previous IVR' and 'harder to pay bills,' had to do with challenges in entering information and completing tasks. When it came to bill payments, the old IVR was praised for doing a better job than the newly implemented one. This was mostly because the new system went through the whole list of previous bills, even if the client preferred not to hear it. Payments were not immediately updated after a bill was paid and it took longer than before to complete the process. Client 123 shared that the IVR could be slower and did not always record all the information entered.

Consequently, it meant always having to connect to a live agent to complete the bill payment process. One of the biggest drivers for client IVR dissatisfaction is clarity - a measure of relative stress when having to provide the same information more than once. Studies show there is as much as a 146-index point drop in NPS when clients have to repeat the same information (Miller, 2017). 
A visually impaired client asked for the IVR to allow more time when entering the card information as it kept timing her out. This was in line with a survey by Dulude (2002) of 44 females, 22 seniors (65-86 years) and 22 university students (18-27 years). According to the survey participants, unclear menu options and fast volume speed negatively impacted the IVR experience. Older participants did not like using the IVR system and found it inconvenient. Results showed a negative relationship between age and overall satisfaction. Speed adaptability of the IVR voice according to a client's profile i.e. a faster voice for Generation Z, Millennials and Generation Xers and a slower voice for Baby Boomers and the elderly could provide a more customized experience.

One of the last two themes was 'better ads/relevant information in the IVR.' This theme was about the lack of relevant information or customization of ads as clients waited on hold. For example, one client talked about how the system kept repeating how to register for online banking even though they were already registered. There were also comments about the lack of variety in the hold music. Adding an option for clients to pick the music genre that interests them and using targeted ads can easily address these issues.

\subsection{IVR Net Promoter Score}

NPS, discussed in Section 3.5, is an industry benchmark created to measure customer loyalty for an organization. It was administered by the company J.D. Power on behalf of the bank under review. This was done by asking how likely the client was to recommend the bank to their family and friends, on a scale of 0-10 with a score 0-6 being a Detractor; 7-8 Passive and 9-10 Promoter (jdpower.com, 2018). Using the data for the 135 
respondents in this research paper, the IVR NPS was calculated on Table 6a below. The IVR NPS was -20. In Table 6b, all the NPS verbatims were divided into two groups based on whether clients made comments about the IVR getting better or getting worse (see Appendix B). Overwhelmingly, $90 \%$ of the feedback was negative and only $10 \%$ was positive.

\section{IVR NPS}

\begin{tabular}{l|l|l}
\hline Promoters & $7 / 135 * 100$ & $5.20 \%$ \\
\hline Passive & $94 / 135 * 100$ & $69.60 \%$ \\
\hline Detractor & $34 / 135 * 100$ & $25.20 \%$ \\
\hline NPS = \%Promoters - \%Passives & $5.2 \%-25.2 \%$ & $\mathbf{- 2 0 . 0 0 \%}$ \\
\hline
\end{tabular}

Table 6a: IVR NPS calculation

\begin{tabular}{|l|c|c}
\hline For better or for worse & IVR better & IVR worse \\
\hline NPS comments about IVR & 24 & 215 \\
\hline Percentage & $10 \%$ & $90 \%$ \\
\hline
\end{tabular}

Table 6b: IVR positive and negative comments

Figure 8 below shows a breakdown of the NPS results depending on whether the respondent was a HVC or not. Passives were at the top of the list in terms of numbers, followed by Detractors and lastly Promoters. Passives were the largest group for both HVC and non-HVCs. Being a Passive meant the client gave a score of seven or eight when asked about their likelihood to recommend the bank to family and friends. The second largest group for NPS were Detractors for both HVC and non-HVCs and these clients would have scored six or less on a ten-point scale. The high number of Passives and Detractors, coupled with the lack of Promoters among both HVC and non-HVCs is a reflection of the level of dissatisfaction with the new IVR system. For every one NPS Promoter, there are 13 Passives or Detractors. 


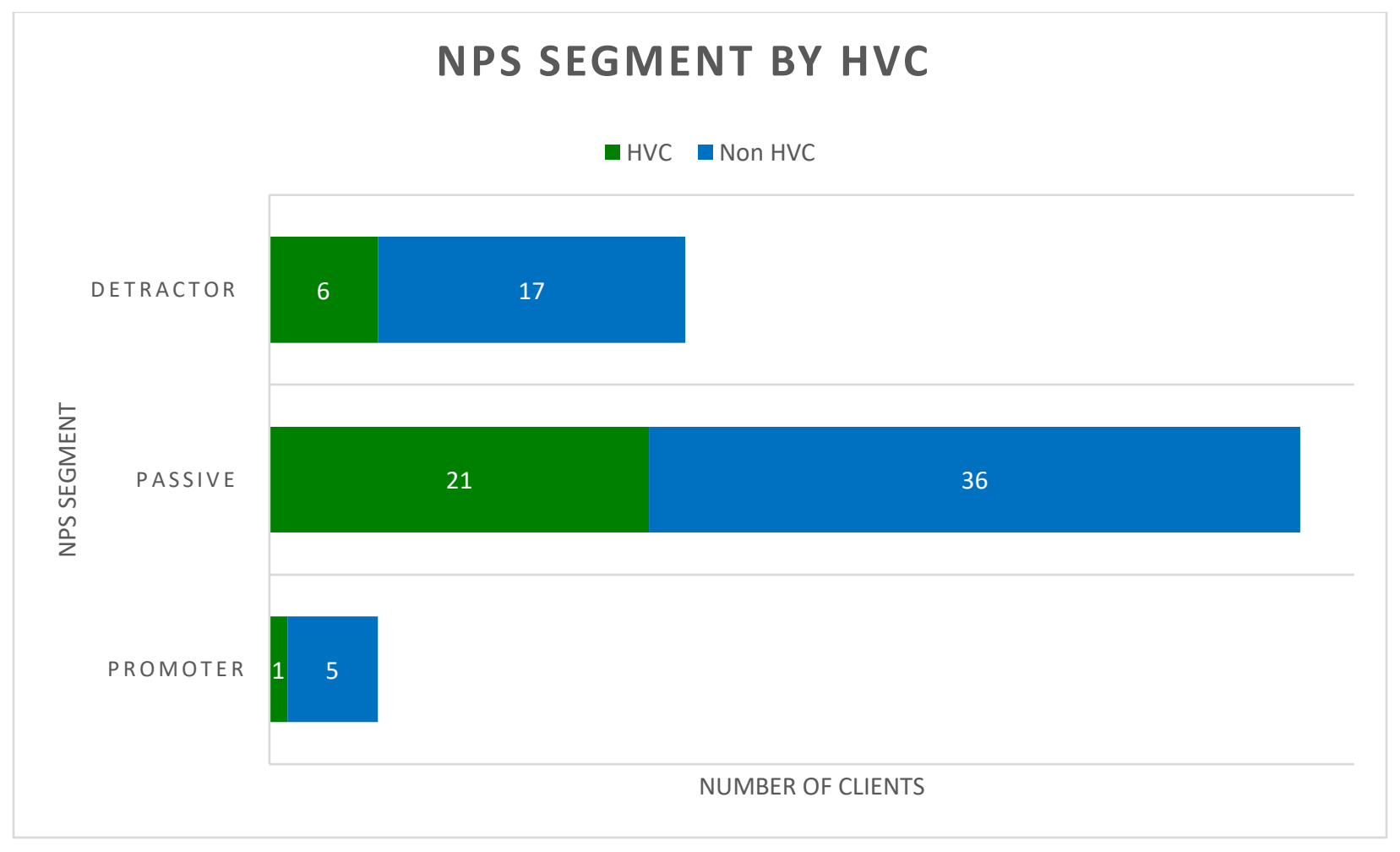

Figure 8: NPS ratings by HVC group

Companies are invested in improving their NPS score because studies show for example that in the beauty, women's clothing and pet food industries, customers who are Promoters spend four times more than Detractors (Markey, 2018). Figure 9 below shows the demographical structure of HVC clients. There is a positive relationship between age and increasing net worth. As individuals age and acquire more assets, the amount of bank products and investments they have increases, which helps strengthen the relationship with their financial institution. The graph shows the number of non-HVC clients decreasing as age increases. With age, clients transition from being non-HVC clients to HVC clients and new investments in IVR SSTs should capture and cater to the aging population. If the IVR is set to identify the demographical cohort a client is in and for example slow the pace of the IVR voice for elderly clients, it means everyone can get the most out of the IVR experience. 


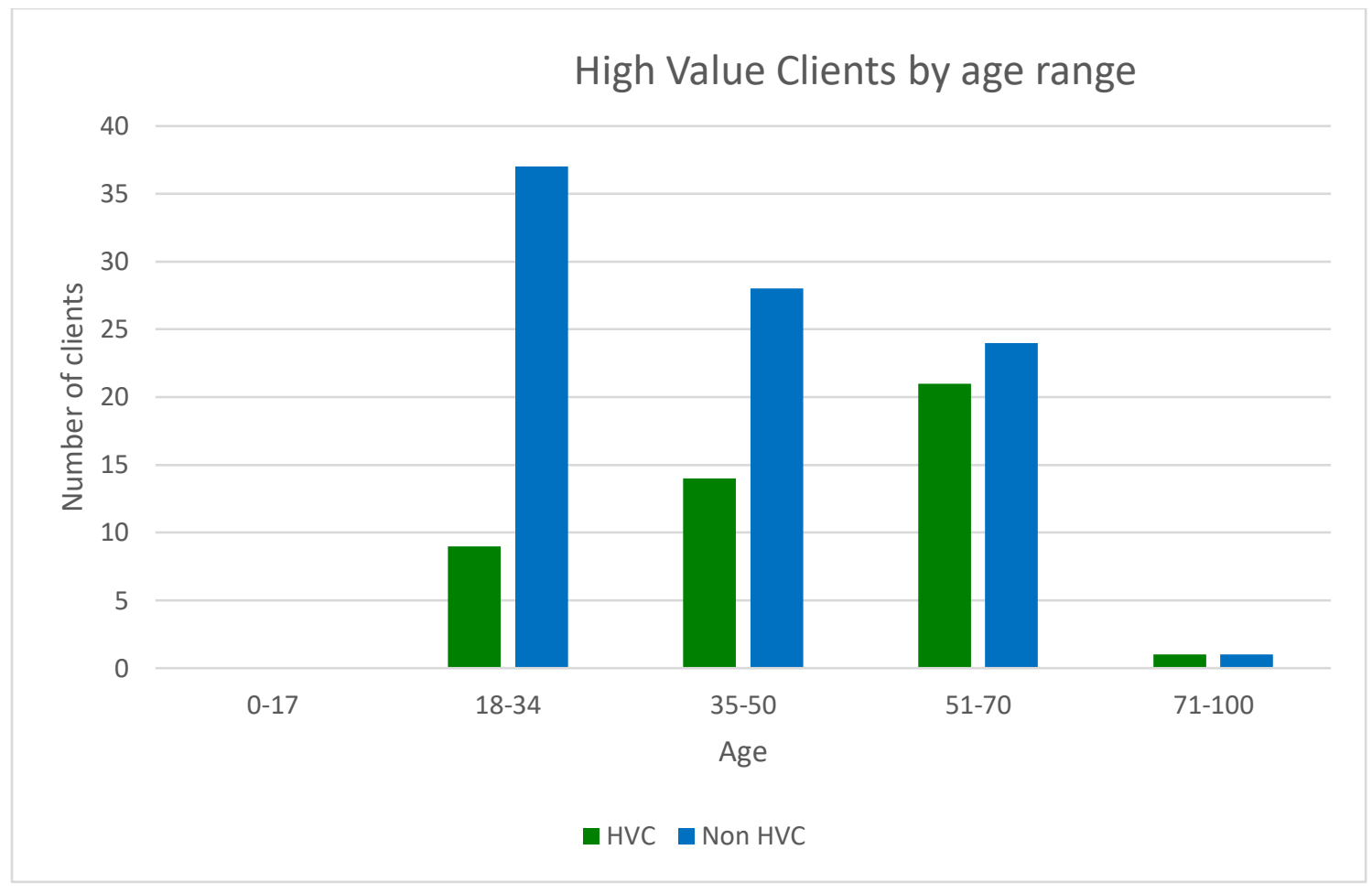

Figure 9: High Value Client group by age

Out of a population of 37 million, 6 million+ Canadians are aged 65 years and over, and by 2030 this number will grow to 9.5 million, over $23 \%$ of the population (Government of Canada, 2014). According to Statistics Canada (2011), as of 2017 there were more seniors than children for the first time in history, and the median age increased to 39.5 years. It is believed that the median age will continue to rise to 44 years by the year 2040 (Statistics Canada, 2011). This means as Baby Boomers (51-70) grow older, the number of seniors will increase. Organizations must ensure that the way they interact and do business caters to an aging population. It will be critical for IVR systems to reflect the demographical changes in the population. Therefore, upgrades and changes to IVR technology should be driven by clients 55 years and older, not by Generation X, Y and Z. After all, as shown from Figure 9, HVC clients increase as age goes up. 
Percentage of respondents open to banking with tech companies

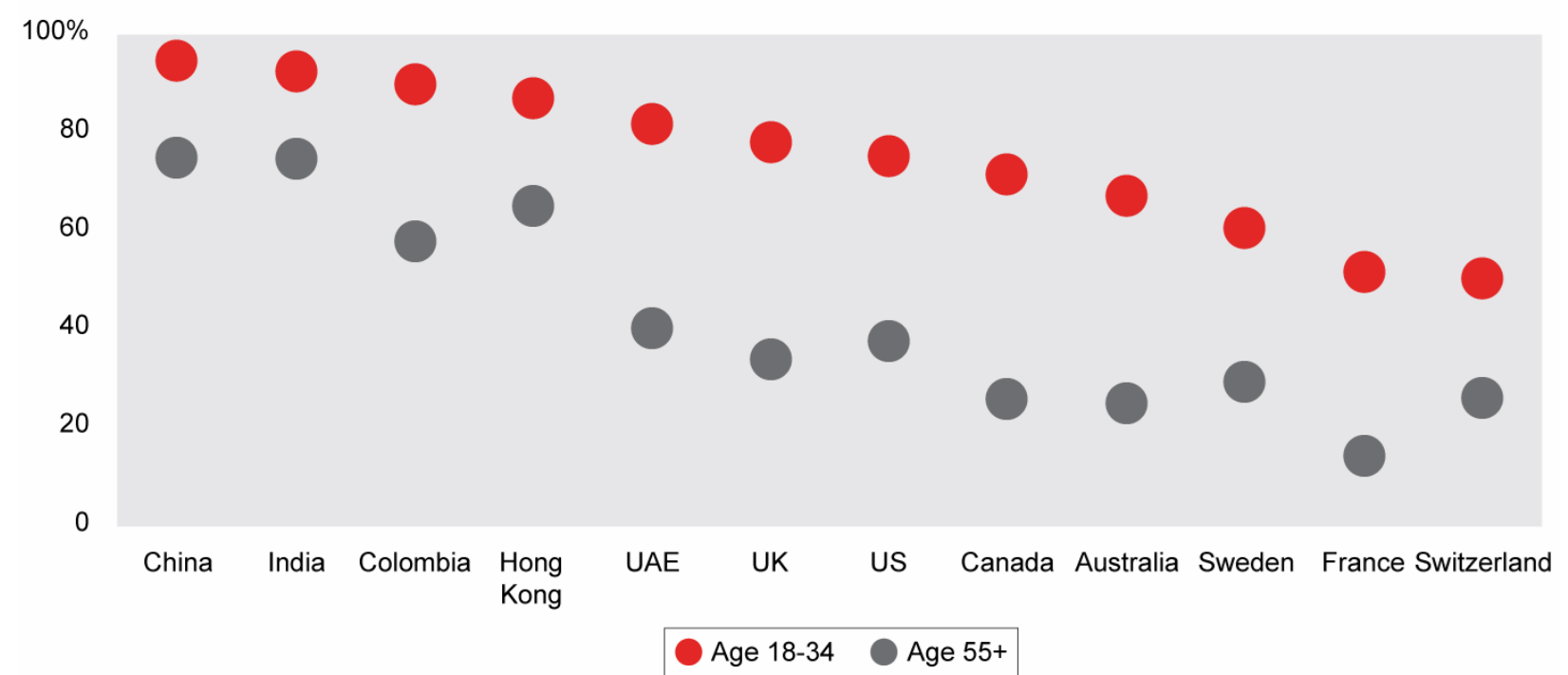

Note: Respondents were asked, "If you needed a new financial product, would you be open to trying a new offering from an established technology company you already use?" (e.g., Google, Apple, Facebook, Alibaba, Tencent)

Source: Bain/Research Now SSI Retail Banking NPS Survey, 2018

Figure 10: Banking and tech companies, Bain and Company, 2018

Figure 10 above shows respondents from different countries that were either between 18-34 years old or 55 years and over. The respondents were asked how open they were to trying a new financial product from a technology company like Google, Apple and Facebook. In Canada, only $20 \%$ of the 55+ age cohort were more likely to try out a product compared to almost $80 \%$ of millennials (du Toit et al., 2018). The older adults showed more loyalty to their primary bank than millennials. An online survey by the market intelligence and advisory firm International Data Corporation (IDC) of over 1000 respondents showed that clients over 50 years old were more likely to be known in person at their local Canadian primary bank and were also more satisfied than those under 50 years, by the service they received (Smythe, et al., 2016). Further, improving IVR technology should include integration with other bank digital channels and mobile 
banking. This is because the Bain and Company research (see Figure 10 above) showed that bank clients that use mobile banking worldwide always give $50 \%$ higher scores for loyalty to their primary bank than low digital clients. These mobile banking clients also have a higher number of banking products, do more transactions and overall are more engaged with their bank (du Toit et al., 2018).

\subsection{So what does this all mean?}

From the thematic analysis (Table 3) and the IVR NPS survey results calculated (Table 6a and 6b), the implementation of the new IVR system has not been well received by clients. Indeed, the new system may be less customer friendly than the old system however comparative data is not readily available. Two factors do come into play to improve the outlook going forward. First, the adoption of new technologies occurs over time as users become better accustomed to the features and functionality of a new system. Second, changes are not made all at once and there are capabilities that can be rolled out with time for example, voice speed and options which can be attuned to the age and preferences of a caller. Unlocking caller identification capabilities such as capturing callers' preferences for voice speed, reason for their last call, etc., the IVR can be used to anticipate caller behaviours and achieve a better client experience.

Based on the theoretical frameworks discussed in Section 2, the results above clearly demonstrate the Productivity Paradox described by Roach (2003) and others. The IVR implementation has failed to generate immediate and short-term improvements as clients appear less satisfied. However, as clients become more acclimatized and the IVR is configured to be more responsive, increased satisfaction should develop. As pointed out by 
Anderson (2018), the vast majority of clients will use self-serve options (83\%) and most want the ability to solve their own problems (73\%). However, Gomez (2018) also points out that adoption rates are low, with $60-70 \%$ of calls ending up with a live agent. It is important to strike a balance as both IVR systems and call centre employees are necessary to achieve great client experience and positive revenue growth (Chessman, 2017). The reality of the financial services sector is that with around the clock service the norm, the challenge it to continually satisfy a heterogeneous client base.

The UTAUT model suggests that even though customers are not pleased with the new IVR system, their pre-existing attitude and intentions are to use the flexibility of the service despite its shortcomings (Venkatesh et al., 2003; Venkatesh et al., 2016). The value to a client is being able to call from anywhere in the world, at any time and that far exceeds the annoyance of a poorly structured IVR menu. As the capabilities of the IVR menu improve, customer expectations and satisfaction should improve as well. After all, usage of the IVR technology is not mandatory. Clients do have the option to utilize more traditional ways to communicate with their bank such as visiting their local branch, using an ATM or online/mobile banking. The IVR offers immediacy and convenience that clients choose to use. Call volumes have increased steadily over the last decade as customers become more familiar with this channel and with the IVR interface. With the growth of digital channels, this trend will continue, as clients call in to contact centres to troubleshoot after interacting with other lines of business. Table 7 below provides a summary of the results of this research. 


\section{Key results from this research}

1. Clients perceive the new IVR to be less friendly as demonstrated by the low NPS score.

2. The bank can adapt the IVR technology to be more responsive to different clients, e.g. voice speed, reason for last call, etc.

3. UTAUT suggests clients will become more familiar with the technology over time.

4. Clients continue to use IVR, despite the technology challenges because of the $24 / 7$ convenience.

Table 7 - Research Results 


\section{Conclusion and Limitations}

There were two research questions to be answered and the first one was, "What is the impact of an Interactive Voice Response (IVR) system upgrade on client experience in the Canadian banking industry?" Using the case study of a Canadian bank, different themes emerged from the data to help answer the research question. The impact of a new IVR system was measured through NPS feedback and the research clearly shows that it was not well received and resulted in a negative client experience.

The second research question was "How is an industry wide benchmark such as NPS affected by an IVR system upgrade?" In the case study of the Canadian bank discussed, NPS results lacked much needed Promoters due to the IVR system upgrade. Participants across different age groups (i.e. Millennials Generation X, Baby Boomers and Elderly) gave a Passive NPS rating when asked how likely they were to recommend the financial institution to family and friends. The IVR NPS was -20 , which is fairly low compared to other banking industry services. To ensure implementation success, a company needs to gain a good understanding of its client base to determine how well it will be received. This can include analyzing demographical data and using feedback on an ongoing basis to adjust and update the business plan.

One of the challenges companies with IVR SSTs face is that the system they put in front of clients to help assist them can remove the very personal connections they are trying to establish (Howard, 2010). A closer look at the thematic analysis shows that the second most coded theme was 'immediate access to an agent' whereas the third strongest theme was 'great customer service.' With immediate access to an agent, clients want the option to speak directly to a CSR and each time they did, they considered it a great 
experience. Therefore, when IVR system support is provided with an adequate number of live agents, companies can find a happy medium that will improve SVLs and satisfy their client base. Of the demographical factors of age and gender explored, gender did not yield any significant insights about IVR system implementation. A study by Vaishnavi and Ganesh (2014) on perceived IVR system frustration among mobile telecommunication clients also yielded similar results. This means that as organizations work to improve their IVR systems, they do not have to make any gender-based adjustments.

A case study of a Canadian bank was used for the research analysis and data was obtained from NPS phone surveys of the bank's clients. They are a few limitations with phone surveys. Those who cannot be contacted or reached via phone e.g. the hearing impaired are excluded, increasing bias (Bryman et al., 2012). Those that are not willing to participate can simply hang up and unlike in person interviews, phone interviews are most likely not to go beyond 20-25 minutes in duration or ask more in depth questions (LewisBeck, et al., 2004). The opportunity to react to verbal cues, leverage visual aids or verify you are speaking to the intended participant is missing from phone interviews (Bryman et al., 2012). The biggest shortcoming for case studies is the risk of bias and the inability of qualitative research to be replicated in the same manner that quantitative research can (Blaikie, 2007). The argument is that case study research is not as rigorous as other methods (Yin, 1989). It is also challenging to generalize the findings of a single case study or compare multiple cases due to their uniqueness (Blaikie, 2007) but this can be easily addressed by doing multiple case studies (Yin, 1989). Another criticism of case studies is the time they take to conduct (Blaikie, 2007) however Yin (1989) argues that case studies can be completed in a timely manner and do not have to take long. 
Other limitations for the research include lack of pre-implementation data as IVR satisfaction was not previously captured by the bank. This could have allowed further analysis to compare any changes or patterns pre and post IVR implementation. Another challenge faced was no to low representation for Generation Z (0-17 years) and the elderly (over 71 years) cohorts as there was lack of feedback received. However, there was more equally distributed representation when it came to Millennials, Generation X and Baby Boomers. Further, the study draws on the on the experiences of 135 IVR users and although insights can be drawn, it is important not to over generalize. The results do provide a foundation that can be explored by future studies on IVR system implementation and client experience. This research is preliminary as the IVR has been in place for only a year and for next steps a reassessment must be done in six to twelve months to measure progress in client satisfaction through NPS verbatims and scores.

This research project has provided a summary of how new IVR systems can change the service clients receive and the resulting impact on customer service benchmarks like NPS. It contributed to the existing body of literature by providing the financial services industry with a blueprint of how to implement a similar IVR system upgrade. Consequently, the goal is to provide a guide and starting point to help future companies that decide to overhaul their IVR systems navigate such a change while maintaining client satisfaction.

In summary, companies planning to upgrade or install an IVR system should expect to see initial dissatisfaction with the new system, as suggested by the Productivity Paradox. The implementation should be sensitive to the demographics (e.g. Boomers, Millennials etc.), and client value segments (e.g. HVC) and structure the IVR to accommodate different customer needs. Prior to implementation, a company should measure client satisfaction 
with the current IVR or call centre, using NPS as a benchmark. Throughout the implementation cycle, client satisfaction should be monitored and any necessary changes made as needed to the IVR system to maintain a high level of satisfaction. Finally, companies implementing IVR technology must recognize that a full set of call centre capabilities, including trained and dedicated CSRs, with well-defined procedures are all required in conjunction with the IVR to create an efficient and successful client interaction. 


\section{Appendices}

\section{Appendix A - Word Frequency chart}

The word cloud summarizes the most commonly used words or phrases found in the survey data. The words appearing most frequently in the cloud are synonymous with many of the recurring themes, for example "person, operator, connected, wait, transfer, directly and representative" are associated with the themes "Immediate access to an agent and Great customer service." The theme "Long and confusing prompts" is associated with other words that stand out like "amount, option and automated."

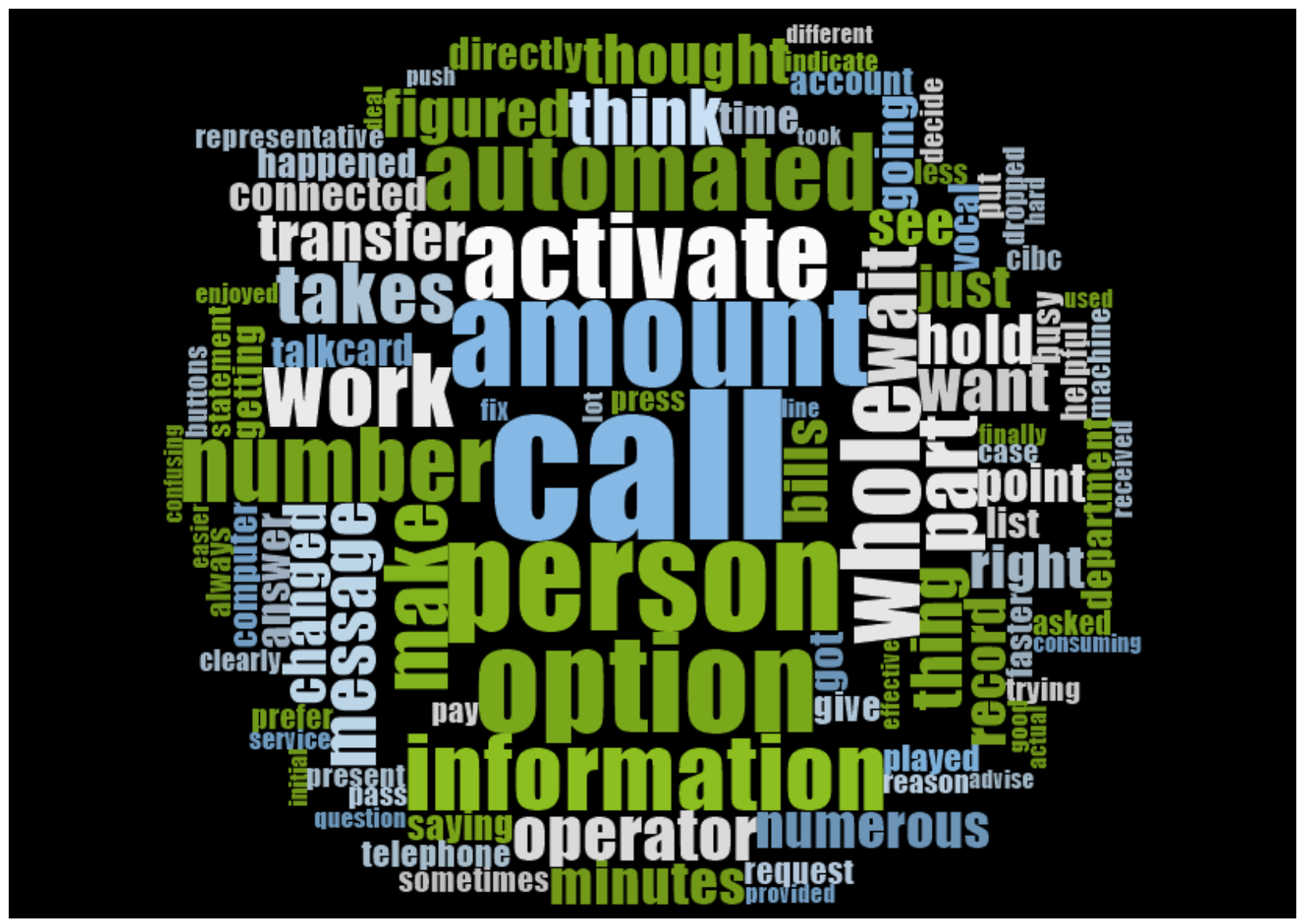




\section{Appendix B}

\section{Raw Data - Themes}

\begin{tabular}{|c|c|c|c|c|c|c|c|c|c|c|c|c|c|}
\hline $\begin{array}{c}\text { Clien } \\
t\end{array}$ & $\begin{array}{c}\text { Long } \\
\text { prompt } \\
\text { s }\end{array}$ & $\begin{array}{c}\text { Access } \\
\text { agent }\end{array}$ & $\begin{array}{l}\text { Cust } \\
\text { serv }\end{array}$ & $\begin{array}{c}\text { Impr } \\
\text { SVL }\end{array}$ & $\begin{array}{c}\text { Worse } \\
\text { than } \\
\text { prev } \\
\text { IVR }\end{array}$ & $\begin{array}{c}\text { Key } \\
\text { issue }\end{array}$ & $\begin{array}{c}\text { Call } \\
\text { back } \\
\text { feat }\end{array}$ & $\begin{array}{l}\text { Drop } \\
\text { calls }\end{array}$ & $\begin{array}{c}\text { Har } \\
\text { d } \\
\text { for } \\
\text { bills }\end{array}$ & $\begin{array}{l}\text { Bette } \\
r \text { info }\end{array}$ & $\begin{array}{c}\text { Bette } \\
\mathbf{r} \\
\text { musi } \\
\mathbf{c}\end{array}$ & $\begin{array}{c}\text { IVR } \\
\text { bette } \\
\text { r }\end{array}$ & $\begin{array}{c}\text { IVR } \\
\text { wors } \\
\text { e }\end{array}$ \\
\hline 1 & 1 & & 1 & & & & & & & & & 1 & 1 \\
\hline 2 & 1 & & & & & & & & & & & & 1 \\
\hline 3 & & & & & 1 & & & & & & & & 1 \\
\hline 4 & & & & & & & & 1 & & & & & 1 \\
\hline 5 & 1 & 1 & 1 & & & & & & & & & 1 & 2 \\
\hline 6 & 1 & & & & & & & & & & & & 1 \\
\hline 7 & 1 & 1 & 1 & 1 & & & & & & & & 1 & 3 \\
\hline 8 & & & & & & & & & & & 1 & & 1 \\
\hline 9 & 1 & 1 & & & & & & & & & & & 2 \\
\hline 10 & 1 & & & & & & & & & & & & 1 \\
\hline 11 & & 1 & & & & & & 1 & & & & & 2 \\
\hline 12 & & & & & & & & & & 1 & & & 1 \\
\hline 13 & & & 1 & & 1 & & & & & & & 1 & 1 \\
\hline 14 & & 1 & & & & & & & & & & & 1 \\
\hline 15 & & 1 & & & & & & & & & & & 1 \\
\hline 16 & & 1 & & & & & & & & & & & 1 \\
\hline 17 & & 1 & & 1 & & & & 1 & & & & & 3 \\
\hline 18 & & & & & 1 & & & & 1 & & & & 2 \\
\hline 19 & 1 & 1 & & & & & & & & & & & 2 \\
\hline 20 & 1 & 1 & & & & & & & & & & & 2 \\
\hline 21 & 1 & & & & & & & & & & & & 1 \\
\hline 22 & 1 & & & & 1 & & & & 1 & & & & 3 \\
\hline 23 & & & 1 & & & & & & & & & 1 & \\
\hline 24 & 1 & & & 1 & & & & & & & & & 2 \\
\hline 25 & 1 & 1 & & & & & & & & & & & 2 \\
\hline 26 & 1 & 1 & & & & 1 & & 1 & & & & & 4 \\
\hline 27 & 1 & 1 & & & & & & & & & & & 2 \\
\hline 28 & & 1 & & & & & & & & 1 & & & 2 \\
\hline
\end{tabular}




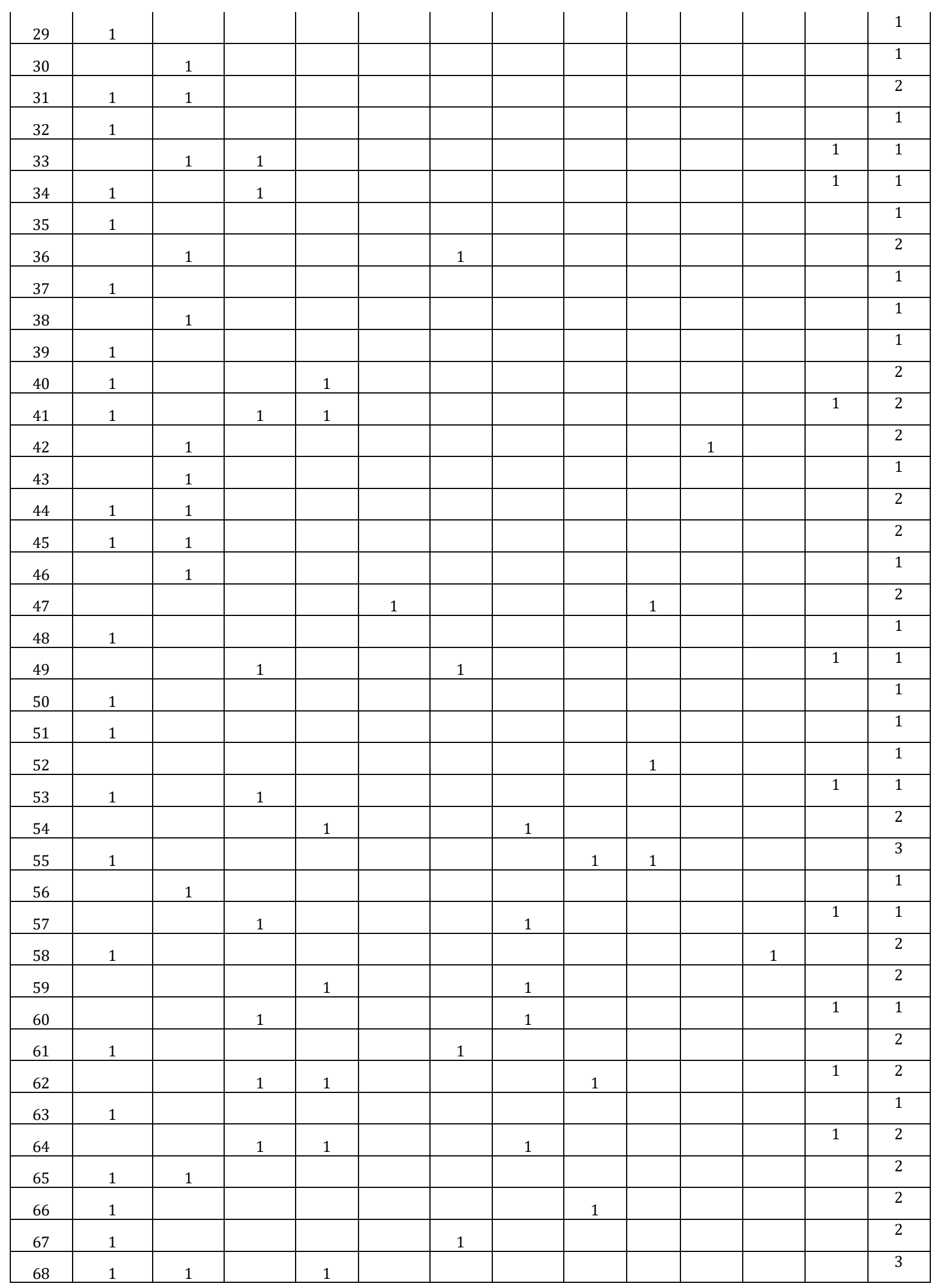




\begin{tabular}{|c|c|c|c|c|c|c|c|c|c|c|c|c|c|}
\hline 69 & 1 & & 1 & & & 1 & & & & & & 1 & 2 \\
\hline 70 & 1 & 1 & & & & & & & & & & & 2 \\
\hline 71 & & & & & & & 1 & & & & & & 1 \\
\hline 72 & & 1 & & 1 & & & & & & & & & 2 \\
\hline 73 & 1 & & & & & 1 & & & & & & & 2 \\
\hline 74 & & 1 & 1 & 1 & & & 1 & & & & & 1 & 3 \\
\hline 75 & 1 & & & & & & & & & & & & 1 \\
\hline 76 & & & & 1 & & & 1 & & & & & & 2 \\
\hline 77 & 1 & & & & & & & & & & & & 1 \\
\hline 78 & 1 & 1 & & & & & & & & & & & 2 \\
\hline 79 & 1 & & & & & & & & & & & & 1 \\
\hline 80 & 1 & & & & & & & & & & & & 1 \\
\hline 81 & & & 1 & & & 1 & & & & & & 1 & 1 \\
\hline 82 & & & & & & & & 1 & & & & & 1 \\
\hline 83 & 1 & 1 & & & & & & & & & & & 2 \\
\hline 84 & 1 & & & & & & & & & & & & 1 \\
\hline 85 & & & & & & 1 & & & & & & & 1 \\
\hline 86 & & & & & 1 & & & & & & & & $\overline{1}$ \\
\hline 87 & & & & & & & & & & & 1 & & 1 \\
\hline 88 & & & & & & & 1 & 1 & & & & & 2 \\
\hline 89 & 1 & 1 & & & & & & & & & & & 2 \\
\hline 90 & 1 & 1 & & & & & & & & & & & 2 \\
\hline 91 & & & & & & 1 & & & & & & & 1 \\
\hline 92 & 1 & & & & & & & & 1 & & & & 1 \\
\hline 93 & 1 & 1 & & 1 & & & & & & & & & 3 \\
\hline 94 & & 1 & & & & & & & & & & & 1 \\
\hline 95 & & 1 & & 1 & & & 1 & & & & & & 3 \\
\hline 96 & 1 & 1 & & & & & & & & & & & 2 \\
\hline 97 & & & 1 & & & & & & 1 & & & 1 & 1 \\
\hline 98 & 1 & & & & & & & & & & & & 1 \\
\hline 99 & 1 & 1 & & & & & & & & & & & 2 \\
\hline 100 & & & & & & & & & & 1 & & & 1 \\
\hline 101 & & 1 & & & & & & & & 1 & & & 1 \\
\hline 102 & 1 & 1 & & & & & & & & & & & 2 \\
\hline 103 & 1 & & & & & & & & & & & & 1 \\
\hline 104 & 1 & & & & & & & & & & & & 1 \\
\hline 105 & 1 & 1 & & & & & & & & & & & 2 \\
\hline 106 & 1 & & & & & & & & & & & & 1 \\
\hline 107 & & & & & 1 & & & & & & & & 1 \\
\hline 108 & & & & & 1 & & & & & & & & 1 \\
\hline
\end{tabular}




\begin{tabular}{|c|c|c|c|c|c|c|c|c|c|c|c|c|c|}
\hline 109 & 1 & & & & 1 & & & & & & & & 2 \\
\hline 110 & & 1 & & & & & & & & & & & 1 \\
\hline 111 & & & & 1 & & & 1 & & & & & & 2 \\
\hline 112 & 1 & 1 & & & & & & & & & & & 2 \\
\hline 113 & 1 & & & & & & & & & & & & 1 \\
\hline 114 & 1 & 1 & & & & & & & & & & & 2 \\
\hline 115 & & & & 1 & & & 1 & & & & & & 2 \\
\hline 116 & 1 & 1 & & & & & & & & & & & 2 \\
\hline 117 & 1 & & 1 & & & 1 & & & & & & 1 & 2 \\
\hline 118 & 1 & 1 & 1 & & & & & & & & & 1 & 2 \\
\hline 119 & 1 & 1 & 1 & & & & & & & & & 1 & 2 \\
\hline 120 & 1 & & & & & 1 & & & & & & & 2 \\
\hline 121 & 1 & & & & & & & & & 1 & & & 2 \\
\hline 122 & & & & & 1 & 1 & & & & & & & 2 \\
\hline 123 & & & 1 & & 1 & 1 & & & 1 & & & 1 & 3 \\
\hline 124 & 1 & 1 & 1 & & & & & & & & & 1 & 2 \\
\hline 125 & 1 & & & & & & & & & & & & 1 \\
\hline 126 & 1 & 1 & 1 & 1 & & & & & & & & 1 & 3 \\
\hline 127 & 1 & & & & & & & & & & & & 1 \\
\hline 128 & & & & & 1 & & & & & & & & 1 \\
\hline 129 & 1 & & & & & & & & & & & & 1 \\
\hline 130 & 1 & & & & & & & & & & & & 1 \\
\hline 131 & 1 & & & & & & & & & & & & 1 \\
\hline 132 & 1 & & & 1 & & & & 1 & & & & & 3 \\
\hline 133 & 1 & 1 & & & & & & & & & & & 2 \\
\hline 134 & & & & & & 1 & & & & & & & 1 \\
\hline 135 & & & & 1 & & & 1 & & & & & & 2 \\
\hline & 79 & 51 & 24 & 20 & 12 & 15 & 13 & 10 & 8 & 6 & 3 & 24 & 215 \\
\hline
\end{tabular}


Appendix C

Approval email to proceed with research

This appendix was removed to maintain confidentiality of the bank under study 
Appendix D

NPS Questionnaire

This appendix was removed to maintain confidentiality of the bank under study 


\section{References}

Adams, Brown, Beran, \& Ball. (2018, February). Make the most of the minimum wage increase. Retrieved from https://www.abbb.com/enewsletter/article/makeminimum-wage

Agarwal, R., \& Prasad, J. (1999). Are individual differences germane to the acceptance of new information technologies? Decision Sciences, 30, 361-391. http://dx.doi.org/10.1111/j.1540-5915.1999.tb01614.x

Anderson, R. (2018, April 11). Contact Center Leaders: If You're Not Early You're Late. Retrieved 17 April 2018, from http://blogs.aspect.com/contact-center-leaders-ifyoure-not-early-youre-late/

Azeta, A. A., Ayo, C. K., Ikhu-Omoregbe, N. A., \& Atayero, A. A. (2009). A Framework for Intelligent Voice enabled E-education systems. Turkish Online Journal of Distance Education-TOJDE, 10(3).

Azeta, A. A., Omoregbe, N. A., Ayo, C. K., \& Atayero, A. A. (2008). Development and Deployment of VoiceXMLgBased Banking Applications. Journal of Computer Science and Its Application, 16(1). Retrieved from http://eprints.covenantuniversity.edu.ng/id/eprint/2146

Bazeley, P., \& Jackson, K. (2013). Quantitative Data analysis with NVivo (Second edition). London: Sage Publications.

Blaikie, N. (2007). Designing Social Research. Polity Press.

Bradshaw, D., \& Kingma, G. (2019). Top 10 Call Centre Metrics and What They Mean to You. Canadian Marketing Assosciation. Retrieved from https://www.thecma.org/disciplines/analytics/archive/top-10-call-centre-metrics 
Braun, V., \& Clarke, V. (2006). Using thematic analysis in psychology. Qualitative Research in Psychology, 3(2), 77-101. https://doi.org/10.1191/1478088706qp063oa

Brouillette, D., Cheung, C., Gao, D., \& Gervais, O. (2017). The Impacts of Mnimum wage increases on the Canadian economy (Staff Analytical Note 2017-26). Ottawa: Bank of Canada. Retrieved from bank-banque-canada.ca

Bryman, A., \& Bell, E. (2007). Business Research Methods (2nd Edition). New York: Oxford University Press.

Bryman, A., Bell, E., \& Teevan, J. (2012). Social Research Methods (Third Canadian Edition). Oxford University Press.

Brynjolfsson, E., \& Hitt, L. M. (1996). Paradox lost? Firm Level Evidence on the Returns to Information Systems Spending. Management Science, 42(4), 541-558.

Brynjolfsson, E., \& Hitt, L. M. (1998, August). Beyond the productivity paradox. Communications of the Association for Computing Machinery, 41(8), 49-55.

Callen, T. (2018, December 18). Gross Domestic Product: An Economy's All. Finance \& Development. Retrieved from https://www.imf.org/external/pubs/ft/fandd/basics/gdp.htm

Campanella, N. (2018, May 8). The State of IVR Systems in 2018. Retrieved 28 February 2019, from https://getvoip.com/blog/2018/05/08/state-of-ivr-2018/

Cearley, D., \& Burke, B. (2018, October 15). Top 10 Strategic Technology Trends for 2019. Gartner. Retrieved from https://www.gartner.com/doc/3891569?srcId=13931087981

Chen, J. (2019, February 11). Return on investment. Investopedia. Retrieved from https://www.investopedia.com/terms/r/returnoninvestment.asp 
Chessman, H. (2017, August 10). We Need To Change How We Approach Customer Experience. Forbes Community Voice. Retrieved 16 April 2018, from https://www.forbes.com/sites/forbescommunicationscouncil/2017/08/10/weneed-to-change-how-we-approach-customer-experience/2/\#19a11cece83b

Dahl, D. (2018). Introduction: Voice XML. Voice XML Forum. Retrieved from http://www.voicexml.org/tutorials-2/introduction/

Davis, F. (1989). Perceived usefulness, perceived ease of use, and user acceptance of information technology. MIS Quarterly, 13(3), 319-340.

Davis, F., Bagozzi, R., \& Warshaw, P. R. (1989). User Acceptance of Computer Technology: A Comparison of Two Theoretical Models. Management Science, 35(8), 982-1003.

Dreyfuss, E., Gadson, A., Riding, T., \& Wang, A. (2008, March). The IT Productivity Paradox. IT Does Matter! Retrieved from http://cs.stanford.edu/people/eroberts/cs201/projects/productivityparadox/background.html

du Toit, G., Bradley, K., Swinton, S., Burns, M., \& de Gooyer, C. (2018, November 14). In Search of Customers Who Love Their Bank. Retrieved 16 March 2019, from https://www.bain.com/insights/in-search-of-customers-who-love-their-bank-npscx-banking/\#

Dulude, L. (2002). Automated telephone answering systems and aging. Behaviour \& Information Technology, 21(3), 171-184. https://doi.org/10.1080/0144929021000013482

Evans, M., \& Ghafourifar, A. (2018, October 20). The Machine Learning Revolution: How Artificial Intelligence Could Transform Your Business. Retrieved from 
https://www.forbes.com/sites/allbusiness/2018/10/20/machine-learning-

artificial-intelligence-could-transform-business/\#44166407c6c3

Farooqi, R., \& Dhusia, D. K. (2011). A comparative study of CRM and e-CRM technologies. Indian Journal of Computer Science and Engineering (IJCSE) ISSN :, 2(4).

Frankenfield, J. (2019, April 17). Online Banking. Retrieved 20 April 2019, from https://www.investopedia.com/terms/o/onlinebanking.asp

Gans, N., Koole, G., \& Mandelbaum, A. (2003). Telephone Call Centers: Tutorial, Review, and Research Prospects. Manufacturing \& Service Operations Management, 5(2), 79-141.

Gomez, R. (2018). Visual IVR. Retrieved 28 February 2019, from

https://www.radial.com/customer-care/visual-ivr

Government of Canada. (2014). (Action for Seniors). Retrieved from

https://www.canada.ca/en/employment-social-development/programs/seniorsaction-report.html

Harper, B. (2017, June 24). Identify and sell more to your most valuable customers. Retrieved from https://www.infoentrepreneurs.org/en/guides/identify-and-sellmore-to-your-most-valuable-customers/

Inam, I., Azeta, A., \& Daramola, O. (2017). Comparative Analysis and Review of Interactive Voice Response Systems (pp. 1-6). Presented at the Conference on Information Communications Technology and Society.

jdpower.com. (2018). Retrieved from https://www.jdpower.com/business/resource/howact-now-nps-and-customer-satisfaction-data

jdpower.com. (2019). Net Promoter Score Measurement and Improvement by J.D. Power. How to Capture and Capitalize on Customer Advocacy - the Pathway to Profitable, 
Sustainable Growth. Retrieved from

https://www.jdpower.com/business/resource/net-promoter-score-measurementand-improvement

Karademir, R., \& Heves, E. (2013). Dynamic interactive voice response (IVR) platform. Presented at the Eurocon 2013, Zagreb, Croatia: IEEE. https://doi.org/10.1109/EUROCON.2013.6624972

Katz, J., Aspden, P., \& Reich, W. (1997). Public attitudes toward voice-based electronic messaging technologies in the United States: A national survey of opinions about voice response units and telephone answering machines. Behaviour \& Information Technology, 16(3), 125-144.

Kenton, W. (2019, February 8). Investopedia: Insights - Money and Economy. Retrieved from https://www.investopedia.com/terms/c/consumerpriceindex.asp

Koivimäki, T., Ristola, A., \& Kesti, M. (2008). The perceptions towards mobile services: An empirical analysis of the role of use facilitators. 12(1), 67-75.

Kreyenhagen, J. (2018, August 30). Why Catering To Mobile Users Is Vital For Today's Services. Retrieved 23 February 2019, from https://www.forbes.com/sites/forbescommunicationscouncil/2018/08/30/whycatering-to-mobile-users-is-vital-for-todays-services/\#42b38d66736a

Leech, N., \& Onwuegbuzie, A. (2011). Beyond constant comparison qualitative data analysis: Using NVivo. School Psychology Quarterly, 26(1), 70-84.

Leppick, P. (2012, February 24). Time to stop talking about 'Containment'. The Customer Service Survey. Retrieved from www.vocalabs.com 
Lewis-Beck, M. S., Bryman, A., \& Futing Liao, T. (2004). The SAGE encyclopedia of social science research methods Thousand Oaks, CA: Sage Publications, Inc. doi: 10.4135/9781412950589. Retrieved from https://dx-doiorg.ezproxy.lib.ryerson.ca/10.4135/9781412950589

Loriggio, P. (2018, November 21). Ontario passes labour reform law, rolls back many Liberal changes. The Canadian Press. Retrieved 9 January 2019, from https://toronto.citynews.ca/2018/11/21/ontario-labour-reform/

MacDonald, S., Anderson, P., \& Kimbel, D. (2000). Measurement Or Management?:

Revisiting the Productivity Paradox of Information Technology. Quarterly Journal of Economic Research, 69(4), 601-617.

Markey, R. (2018, May 11). New Bain Certified NPS Benchmarks: Companies Customers Love. Retrieved from https://www.bain.com/insights/new-bain-certified-npsbenchmarks-companies-customers-love/

Microsoft Corporation. (2010). Measuring IVR performance (Tellme) (pp. 1-11). CA. Retrieved from www.tellme.com/business/resource_center\#performance Miles, M., \& Huberman, M. (1994). Qualitative Data Analysis (Second Edition). CA: Sage Publications.

Miller, D., Bruce, H., Gagnon, M., \& Messier, C. (2011). Improving older adults' experience with interactive voice response systems. Telemedicine Journal and E-Health, 17(6), 452-455. https://doi.org/10.1089/tmj.2010.0204

Miller, M. (2017). 2017 Top Drivers of Customer Satisfaction in the IVR and Live Phone Channels and How Advanced Dialogue Can Shape the Experience. Retrieved from 
https://www.jdpower.com/business/resource/top-drivers-customer-satisfactionivr

Minimum wage increase. (2018, February). Retrieved from https://www.ontario.ca/page/minimum-wage-increase

Ngo, L., Rhodes, N., \& West, D. (2017, September 12). Assessing the Economic Impact of Ontario's Proposed Minimum Wage Increase. fao commentary. Retrieved from fao.on.org

Perry, A. R., \& Wingfield, A. (1994). Contextual encoding by young and elderly adults as revealed by cued and free recall. Aging and Cognition, 1, 120-139.

qsrinternational.com. (2018). Retrieved 14 April 2018, from http://helpnv11.qsrinternational.com/desktop/procedures/run_a_coding_comparison_query.h $\mathrm{tm}$

Roach, S. (2003, November 30). The Productivity Paradox. The New York Times. Retrieved from http://www.nytimes.com/2003/11/30/opinion/the-index-of-missingeconomic-indicators-the-productivity-paradox.html

Roberts, P., Priest, H., \& Traynor, M. (2006). Reliability and validity in research Nursing Standard (through 2013). Nursing Standard (through 2013), 20(44), 41-45.

Schroder, K., \& Johnson, C. (2009). Interactive Voice Response Technology to measure HIV related behaviour (Current HIV/AIDS Reports) (pp. 1-8). Logan, UT: Department of Psychology , Utah State University. Retrieved from https://www.researchgate.net/profile/Kerstin_Schroder/publication/38029547_In teractive_voice_response_technology_to_measure_HIV- 
related_behavior/links/00463522bfe9e0d199000000/Interactive-voice-responsetechnology-to-measure-HIV-related-behavior.pdf

Sharit, J., Czaja, S., Nair, S., \& Lee, C. C. (2001). Age group differences in subjective perceptions of telephone voice menu systems (pp. 216-220). Presented at the Human Factors and Ergonomics Society 45th Annual Meeting.

Sheppard, B. H., Hartwick, J., \& Warshaw, P. R. (1988). The theory of reasoned action: A meta-analysis of past research with recommendations for modifications and future research. Journal of Consumer Research, 15(3), 325-343.

Sherif, Y., Simske, S., Lin, X., \& Burns, J. (2003). Recognition of Emotions in Interactive Voice Response Systems. In Eurospeech 2003. Geneva, Switzerland.

Smith, S. (2012, November 5). 9 Key Stages in the Marketing Research Process. Retrieved 15 April 2018, from https://www.qualtrics.com/blog/marketing-research-process/

Smythe, R., \& Bremner, J. (2019). Canadian Financial Services Survey: Consumer Financial Services Preferences, 2018 (No. \#CA44506419; pp. 1-22). Retrieved from IDC Canada website: www.idc.com

Smythe, R., Burbach, R., \& Schrutt, M. (2016a). Perspective: Demographic and Technology Personas of Canadian Bank Clients in a Digital World (IDC Financial Insights No. \#CA40484416; pp. 1-36). Retrieved from IDC Canada website: www.idc.com

Smythe, R., Burbach, R., \& Schrutt, M. (2016b). Perspective: Product and Services Experiences and Expectations of Canadian Bank Clients in a Digital World (IDC Financial Insights No. \#CA40500216; pp. 1-45). Retrieved from www.idc.com

Solomon, M. (2015, April 8). Omnichannel Customer Experience: Expert Systems, 360 Degree Views And AI. Retrieved 20 April 2019, from 
https://www.forbes.com/sites/micahsolomon/2015/04/08/omnichannel-

customer-experience-how-a-360-degree-view-of-customer-care-canhelp/\#4b47866db764

Soujanya, M., \& Kumar, S. (2010). Personalized IVR system in Contact Centre (Vol. 1, pp. 453-457). Presented at the International Conference on Electronics and Information Engineering.

Statistics Canada. (2011). statcan.gc.ca (Population and demography No. 11-402- X) (pp. 352-365). Retrieved from www.statcan.gc.ca

Straub, E. (2009). Understanding Technology Adoption: Theory and Future Directions for Informal Learning. Review of Educational Research, 79(2), 625-649.

Sun, Y., Bhattacherjee, A., \& Ma, Q. (2009). Extending technology usage to work settings: The role of perceived work compatibility in ERP implementation. Information and Management, 46(4), 351-356.

Taylor, K., \& Silver, L. (2019, February 5). Smartphone Ownership Is Growing Rapidly Around the World, but Not Always Equally. Retrieved 23 February 2019, from http://www.pewglobal.org/2019/02/05/smartphone-ownership-is-growingrapidly-around-the-world-but-not-always-equally/

Tencer, D. (2019, February 9). Did Ontario's Minimum Wage Hike Kill Jobs? A Look At The Numbers, 1 Year Later. Huffington Post. Retrieved from https://www.huffingtonpost.ca/2019/02/09/ontario-minimum-wageimpact_a_23665531/ 
Thirumaran, M., Soni, S., \& Brendha, G. (2015). An Intelligent Interactive Voice Response System for Banking Domain. Presented at the 2015 International Conference on Advanced Research in Computer Science Engineering and Technology.

Triplett, J. (1999). The Solow Productivity Paradox: What do Computers do to Productivity? The Canadian Journal of Economics, 32(2), 309-334.

Tseng, S. M. (2008). The effects of information technology on knowledge management systems. Expert Systems with Applications, 35(1-2), 150-160. https://doi.org/10.1016/j.eswa.2007.06.011

Tuckett, A. (2005). Applying thematic analysis theory to practice: A researcher's experience. Contemporary Nurse - Journal for the Australian Nursing Profession, 19(1-2), 75-87. https://doi.org/10.5172/conu.19.1-2.75

Turner, D. (2018). aspect.com. Retrieved 25 November 2017, from https://www.aspect.com/solutions/self-service/ivrsystems?_bt=200331159728\&_bk=\%2Baspect\%20\%2Bivr\&_bm=b\&_bn=g\&gclid=Cj 0KCQiAg4jSBRCsARIsAB9ooasEDuhiGyGi8WZ42GjJKg8sU3jsro3BhuFOAaf2bBTcT mVOhshdwEoaAj26EALw_wcB

Vaishnavi, G., \& Ganesh, S. (2014). Effects of customer demographics on perceived frustration towards 'interactive voice response systems' of mobile telecommunication services. International Journal of Research in Business Management, 2(6), 13-18.

Venkatesh, \& Davis, F. (2000). A Theoretical Extension of the Technology Acceptance Model: Four Longitudinal Field Studies. Management Science, 46(2), 186-204. https://doi.org/10.1287/mnsc.46.2.186.11926 
Venkatesh, Morris, M. G., Davis, G. B., \& Davis, F. D. (2003). User acceptance of information technology: Toward a unified view. MIS Quarterly, 27(3), 425-478. https://doi.org/10.1287/mnsc.35.8.982

Venkatesh, V., Thong, J., \& Xu, X. (2016). Unified Aceptance and Use of Technology: A sysnthesis and the road ahead. Journal of the Association for Information Systems, $17(5), 328-376$.

Yin, R. (1989). Case Study Research: Design and Methods (Vol. 5). Beverly Hills, CA: Sage. Zhou, T., Lu, Y., \& Wang, B. (2010). Integrating TTF and UTAUT to explain mobile banking user adoption. Computers in Human Behavior, 26(4), 760-767. 


\begin{tabular}{|c|c|}
\hline \multicolumn{2}{|l|}{ Glossary } \\
\hline AI & $\begin{array}{l}\text { Artificial Intelligence - the adaptation and simulation of human behaviours and } \\
\text { tasks by computers } 1\end{array}$ \\
\hline CPI & $\begin{array}{l}\text { Consumer Price Index - an average measure of the changes of a basket of goods } \\
\text { and services pegged to a base year and measures a nation's cost of living over } \\
\text { time }^{2}\end{array}$ \\
\hline CRM & $\begin{array}{l}\text { Customer Relationship Management - the process of acquiring, retaining and } \\
\text { growing profitable customers }{ }^{3}\end{array}$ \\
\hline CSR & $\begin{array}{l}\text { Customer Service Representative - an employee responding to and fulfilling } \\
\text { client requests }\end{array}$ \\
\hline GDP & $\begin{array}{l}\text { Gross Domestic Product - the total value of goods and services produced by a } \\
\text { country over a period of time e.g. one year } 4\end{array}$ \\
\hline HVC & $\begin{array}{l}\text { High Value Clients - select group of customers that are the most profitable to a } \\
\text { business } 5\end{array}$ \\
\hline IT & $\begin{array}{l}\text { Information Technology - the use of systems such as computers to store, move, } \\
\text { process, manipulate and send data electronically including software, hardware } \\
\text { and related services } 6\end{array}$ \\
\hline IVR & $\begin{array}{l}\text { Interactive Voice Response - IT system that uses voice prompts and menus to } \\
\text { present information and options to callers } 7\end{array}$ \\
\hline NPS & $\begin{array}{l}\text { Net Promoter Score }- \text { A measure of customer loyalty and advocacy derived } \\
\text { from asking the question "How likely are you to recommend Company X to } \\
\text { family and friends on a scale of } 0-10 \text { ?" Score } 0-6=\text { Detractor; } 7-8=\text { Passive; } 9- \\
10=\text { Promoter }^{8}\end{array}$ \\
\hline ROI & Return on Investment - measure of the profitability/gain from an investment ${ }^{9}$ \\
\hline SST & $\begin{array}{l}\text { Self-Serve Technology - a system that allows customers to obtain information } \\
\text { or services without the assistance of a live agent } 10\end{array}$ \\
\hline SVL & $\begin{array}{l}\text { Service Levels - the percentage of calls answered within a preset threshold e.g. } \\
\text { if SVL target is } 80 / 20 \text { then } 80 \% \text { of calls must be answered within } 20 \text { seconds } 11\end{array}$ \\
\hline $\begin{array}{l}\text { TAM } / 2 / 3 \\
\text { and } \\
\text { UTAUT }\end{array}$ & $\begin{array}{l}\text { Technology Acceptance Model } / 2 / 3 \text { and Unified Theory of Acceptance and Use } \\
\text { of Technology models - evolved theoretical frameworks for system use that } \\
\text { focus on usefulness and perceived ease of use }{ }^{12}\end{array}$ \\
\hline $\begin{array}{l}\text { Voice } \\
\text { XML }\end{array}$ & $\begin{array}{l}\text { Voice eXtensible Markup Language - open standard markup language for voice } \\
\text { applications } 13\end{array}$ \\
\hline
\end{tabular}

1 (Evans \& Ghafourifar, 2018)

${ }^{2}$ (Kenton, 2019)

${ }^{3}$ (Farooqi \& Dhusia, 2011)

${ }^{4}$ (Callen, 2018)

5 (Harper, 2017)

${ }^{6}$ (Cearley \& Burke, 2018)

${ }^{7}$ (Turner, 2018)

8 (jdpower.com, 2019)

9 (Chen, 2019)

${ }^{10}$ (Vaishnavi \& Ganesh, 2014)

11 (Bradshaw \& Kingma, 2019)

12 (Vaishnavi \& Ganesh, 2014)

${ }^{13}$ (Dahl, 2018) 